\title{
Title: Characterization of gliadin, secalin and hordein using advance analytical techniques
}

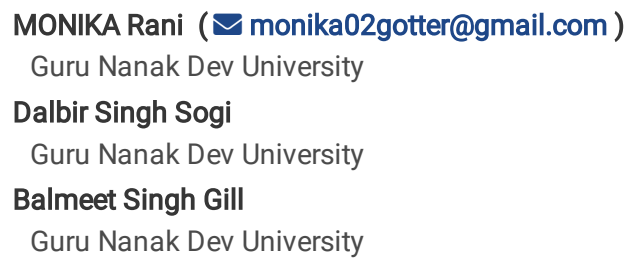

Version of Record: A version of this preprint was published at Scientific Reports on November 30th, 2021. See the published version at https://doi.org/10.1038/s41598-021-02099-0. 


\section{Abstract}

Prolamins extracted from wheat, rye and barley cultivars were analysed for colour characteristics, SDS-PAGE, Amino Acid, Dynamic Light Scattering (DLS), Zeta Potential, Scanning Electron Microscopy (SEM), Energy Dispersive X-Ray (EDX), Transmission Electron Microscopy (TEM) and X-ray Diffraction (XRD) to elucidate the structure. Amino acid analysis showed significant variation among the prolamins and the predominant essential amino acids were found to be leucine, phenylalanine and valine whereas predominant non-essential amino acids were glutamic acid, arginine and aspartic acid. All the prolamins exhibited positive zeta-potential, however gliadin had a significantly higher zeta potential value. TEM studies of prolamins revealed the compact globular structure but gliadin also had rod-shaped structure. Morphology by SEM illustrated the globular particle arrangement in gliadin and sheet like arrangement in secalin and hordein. XRD pattern of prolamin showed the ordered crystalline domain of prolamin at $44.1^{\circ}, 37.8^{\circ}$ and $10.4^{\circ}$. The $\mathrm{d}$-spacing obtained from XRD and TEM analysis also supports the crystalline domain of prolamin apart from amorphous domain.

\section{Introduction}

Prolamin is a group of heterogeneous mixture of alcohol soluble polypeptide (30-75 kDa MW) chains, which constituted the major storage protein of Triticeae tribe, usually known as gliadin in wheat, secalin in rye and hordein in barley. The members of this tribe share closely resembled storage proteins. The etymology of prolamin is derived from amino acid repetitive motifs of proline and amide nitrogen from glutamine in primary sequence of storage protein and low content of basic amino acids ${ }^{1}$. The prolamins are known to triggers the immunological disorder to gene coded for leukocytic HLADQ2/HLA-DQ8 antigen leading to celiac or coeliac disease (CD) in genetically susceptible individuals while other food hypersensitivities such as gluten sensitivity and non-coeliac allergies are also associated with gluten protein of aforementioned grains ${ }^{2}$. A recent meta-analysis revealed that the global $C D$ pooled sero-prevalence was about $1.4 \%$. In the beginning CD was considered as European or Western disease but now have been reported globally with prevalence in Europe and Oceania (0.8\%), Asia (0.6\%), Africa and North America (0.5\%) and South America $(0.4 \%)^{3}$. Main factors for its dissemination are dietary, genetic, emergence of new antigenic strain of wheat and also agricultural practices. However, in Saharawi individuals (especially infants) of Africa originally from Western Sahara showed very high incidence of this disorder in 5.6\% population. The probable reason of more prevalence in African people was related to genetic, environmental as well drastically abrupt change in Bedouin dietary from breastfeeding, camel milk, dates, sugar, and less cereal consumption to processed wheat products especially bread as staple food ${ }^{4}$. In India, CD prevalence was more in wheat consuming states i.e. northern population $(\approx 1.2 \%)$ than rice consuming states i.e. southern population $(\approx 0.13 \%)^{3}$. Apart from this, prolamin is also gaining research interest as potential plant-based source for hydrogels, films and nano-particle for controlled drugs and phytochemicals delivery ${ }^{5-7}$. Till date, only gliadin nanoparticles have been successfully used for the delivery of drugs and nutrients ${ }^{6-8}$.

Numerous protocols are available for the extraction of prolamin but only a few could extract the prolamin without glutenin cross contamination especially with LMW-glutenin sub unit due to their similar genetic characteristics and trapping of prolamin in the glutenin polymeric network via disulphide linkages ${ }^{9}$. Fu \& Kovacs, ${ }^{10}$ reported a prolamin extraction protocol which was modified by ${ }^{11}$, for claiming the complete extraction of prolamin, free from glutenin cross contamination, with short i.e. single step protocol, less labour intensive, high resolution/ reproducibility and coherent protocol.

Abundant publications are available on gliadin while a scanty research has been conducted on secalin and hordein for their molecular and chemical profile. However, this information is beneficial for clinical studies, pharmaceutical industries and research scientist for better understanding of its behaviour under different applications. Field et al., ${ }^{12}$ studied the purification and characterization of secalin via electrophoresis, chromatography, amino acid composition/sequencing and compared it with the reported values of gliadin and hordein. Ribeiro et al., ${ }^{13}$ studied the polymorphism among storage protein of Portuguese rye cultivars and postulated that rye cultivars were good genetic resource for breeding purposes due to their effective gene traits such as nutritional proficiency (especially dietary fibre), disease tolerance, effective production with minimum pesticide and fertilizers application.

The morphology and biochemical characterization of secalin and hordein have not been studied extensively. Recent advances have improved the molecular basis for better understanding of protein functionality. So, an attempt has been made to achieve structural, chemical and molecular characterization of prolamins by using a multi-disciplinary approach via protein peptide profiling (SDS-PAGE), protein hydrodynamic size (DLS), net surface charge (Zeta-potential), structural morphology (SEM and TEM), elemental status (EDX) and internal molecular structure (XRD and TEM).

\section{Materials And Methods}

Materials. All the experimental work and collection of samples was done in accordance with the relevant national and international guidelines. The permission for collection and use of cultivated cereal grains of rye cultivars (MCTLG-1, MCTLG-2, MCTLG-3, MCTLG4 and MCTLG-5) and wheat cultivars (HPW-42, HPW-147, HPW-155, HPW-236, HPW-249 and HPW-349) were obtained from agricultural university: Chaudhary Sarwan Kumar Himachal Pradesh Krishi Vishvavidyalaya (CSK HPKV), Palampur, India, which is located at latitude $32^{\circ} 6^{\prime} 52^{\prime \prime} \mathrm{N}$ longitude $76^{\circ} 33^{\prime} 24^{\prime \prime} \mathrm{E}$, and altitude $1614 \mathrm{~m}$ above sea level. The formal identification of rye and wheat cereal cultivars was carried out by Dr. H. K. Chaudhary, Professor and Head of Genetics, Plant Breeding and Agricultural Biotechnology at CSK Himachal Pradesh Agriculture University, Palampur. The barley cultivars (BH-393, BH-902, BH-946 and BH959) were obtained from Chaudhary Charan Singh Haryana Agricultural University (CCS HAU), Hisar, India latitude 29 8’ 57.08” N, longitude $75^{\circ} 43^{\prime} 17.95^{\prime \prime} \mathrm{E}$ and altitude $212.78 \mathrm{~m}$ above sea level, identified by Dr S. K. Datta, Deputy Director General (Crop Sciences), Indian Council of Agriculture Research (ICAR). Brabender Quadrumat Junior Mill (Brabender OHG, Duisburg, Germany) 
was used to mill the conditioned grains to obtained flour having extraction rate of $72 \%$, $68 \%$ and $60 \%$ for wheat, rye, and barley respectively. It was stored at $-20^{\circ} \mathrm{C}$ and thaws before analysis $\left(25^{\circ} \mathrm{C}\right.$ for $2 \mathrm{~h}$ ). All the chemicals used were of analytical grade.

\section{Methods}

Prolamin extraction. Prolamin was extracted from wheat, rye and barley by following 11 . Briefly, $1 \mathrm{~g}$ of flour was taken in $10 \mathrm{~mL}$ extraction solution (0.3 M NaI solution containing 7.5\% 1-propanol), shaken for 20 min and centrifuged (5810R, Eppendorf, Hamburg, Germany) for $10 \mathrm{~min}$ at 4500xg to collect the supernatant. Extraction process was repeated with the residues. The supernatants of both the fractions were pooled and transferred to round-bottom glass flask. Four times volume of $0.1 \mathrm{M}$ ammonium acetate in methanol was added to the pooled supernatant, shaken thoroughly and kept at $-20^{\circ} \mathrm{C}$ for $48 \mathrm{~h}$ to precipitate the prolamins. The solution was centrifuged at 3600xg (5810R, Eppendorf, Hamburg, Germany) to obtain the prolamin fraction as pallet. The precipitates were dissolved in $0.1 \mathrm{M}$ acetic acid and also washed from the sides of the glass tube with $0.1 \mathrm{M}$ acetic acid and freeze dried (HetoPowerDry, Allerod, Denmark). Samples were stored in airtight plastic vials at $-20^{\circ} \mathrm{C}$ for further use.

Protein Determination. Protein content was measured in triplicate by the Kjeldahl method $(N \times 5.70)$ following American Association of Cereal Chemists (46-12.01) ${ }^{14}$.

Color of prolamin. The color of prolamin was measured using Hunter Colour lab (Hunter Associates Laboratory Inc., Reston, USA) by following ${ }^{15}$. The instrument was calibrated with black and white standard tiles and then samples (extracted prolamin) were measured using glass cuvette. CIE units consist of L* (lightness) ranges from 0 to 100, a* (+red, -green color) and b* (+yellow, -blue color) were recorded.

The hue angle $\left(\mathrm{H}^{\circ}\right)$ is a color appearance parameter which refers as quantitative attribute of color lies between an angle of $0^{\circ}-360^{\circ}$ with $0^{\circ}$ representing red, $90^{\circ}$ for yellow, $180^{\circ}$ for green and $270^{\circ}$ for blue. While, Chroma refers to intensity of color purity or color strength. It is expressed as either grey or the pure hue (red/yellow/green/ blue etc).

Hue and Chroma were calculated using the following Equations:

$$
\begin{aligned}
\text { Hue angle }\left(\mathrm{H}^{\circ}\right) & =\tan ^{-1}\left(\mathrm{~b}^{* / \mathrm{a}^{*}}\right)^{2} . \\
\text { Chroma }\left(\mathrm{C}^{*}\right) & =\left(\mathrm{a}^{* 2}+\mathrm{b}^{* 2}\right)^{0.5}
\end{aligned}
$$

Dynamic Light Scattering (DLS) Measurements. The hydrodynamic diameter $\left(D_{h}\right)$ and zeta potential ( $\zeta$-potential) values of proteins were monitored on Zetasizer Nano ZS (Malvern Instruments Ltd., Worcestershire, UK) equipped with a He-Ne laser (632.8 nm, 4 $\mathrm{mW}$ ), at back scattering angle of $173^{\circ}$ to the incident beam and operated at $25^{\circ} \mathrm{C}$. The instrument monitors, time-dependent fluctuation in the light scattered by molecules present in solution to determine the diffusion rate due to the Brownian motion at a fixed scattering angle. The extracted prolamin(s) (1 $\mathrm{mg} \mathrm{ml}^{-1}$ ) were prepared in acetonitrile: water: formic acid (50:50:0.1) solution. To avoid the formation of protein aggregates, the samples were vortexed gently and then filtered through 0.22 mm Millipore filters prior to measurements. An average of three measurements for each sample was considered as an experimental data.

SDS-PAGE of Prolamin. Sodium Dodecyl Sulphate-Polyacrylamide Gel Electrophoresis (SDS-PAGE) was used to analyse the variability of extracted prolamin in terms of genetic diversity by adopting the method of 15 . $10 \mathrm{mg}$ of prolamin was thoroughly mixed with $1 \mathrm{ml}$ of $2 \mathrm{x}$ Laemmli sample buffer solution (pH 6.8 containing $62.5 \mathrm{mM}$ Tris-HCl, 25\% glycerol, 5\% 3 -mercaptoethanol, $2 \%$ SDS, $0.01 \%$ bromophenol blue) in $1.5 \mathrm{ml}$ Eppendorf tubes. The suspension was vortexes followed by horizontal shaking in orbital shaker operated $\left(45^{\circ} \mathrm{C}\right)$ for $1 \mathrm{~h}$ at $151 \mathrm{rpm}$. Then after subjected to heating at $100^{\circ} \mathrm{C}$ for 5 mins followed by centrifugation (RC $4815 \mathrm{~S}$, Eltek, Mumbai, India) at 11000xg for 20 mins.

SDS-PAGE of prolamin was performed by loading $10 \mu \mathrm{l}$ of prepared sample supernatant in each well of $4 \%$ stacking gel and loaded proteins were resolved in 12\% resolving gel at a constant current of 25 mA (Mini-Protean Tetra Cell, Bio-Rad Laboratories, Hercules, USA).

When the tracking dye reached at the bottom of gel then gel was removed and stained overnight with straining solution which had a composition of $0.1 \%$ Coomassie Brilliant Blue-R250 in $40 \%$ methanol along with $10 \%$ acetic acid. To remove stain, destaining solution was used which was prepared by dissolving $20 \%$ methanol and $10 \%$ acetic acid.

The broad range molecular marker (GeNei, Bangalore, India) contains nine ladder Molecular Weight (MW) of myosin (205 kDa), phosphorylase B (97.4 kDa), bovine serum albumin (66.0 kDa), ovalbumin (44.0 kDa), carbonic anhydrase (29.00 kDa), soyabean trypsin inhibitor (20.10 kDa), lysozyme (14.30 kDa), aprotinin (6.50 kDa) and insulin (3.50 kDa) was used for estimation of MW of sample polypeptide. The quantification of destained gel was analysed by using Bio-Rad EZ imager (Bio-Rad Laboratories, Hercules, USA).

Classification of total prolamin was done according to ${ }^{16}$. The relative proportion of prolamin was calculated using band percentage corresponding to the total extractable proteins. SDS-PAGE gels were performed in duplicates. 
Amino acid analysis of prolamin. Analysis of prolamin was performed by following the procedure of 15 with slight modification. Briefly, $5 \mathrm{mg}$ of prolamin were hydrolysed in clean dried screw capped glass test tubes which were priorly dipped whole night in $2 \mathrm{~N}$ $\mathrm{HCl}$ to avoid any sort of contamination. Hydrolysis was carried out using $6 \mathrm{~N} \mathrm{HCl}$ containing $0.1 \% \beta$-mercaptoethanol in autoclave at $110^{\circ} \mathrm{C} \pm 2^{\circ} \mathrm{C}$ for $16 \mathrm{~h}$ in screw tight capped closure test tubes to minimize the loss of digestion solvent during hydrolysis process. The filtrate was evaporated in a small round bottomed rotary flask under vacuum at $40^{\circ} \mathrm{C}$ to dryness in a rotary evaporator (Buchi, Fawil, Switzerland). A suitable volume of $0.1 \mathrm{~N} \mathrm{HCl}$ was added to each dried film of the hydrolyzed sample to dissolve all the soluble materials and then filtered through $0.22 \mu \mathrm{m}$ filter paper (Millipore, Merck Life Science Private Limited, Mumbai, India). Amino acid analysis was performed using a Nexera Amino acid Analyzer (Shimazdu, Kyoto, Japan) equipped with a pre-column derivatization using three derivatizing reagents such as mercaptopropionic acid, o-phthaladehyde and 9-fluorenylmethyl chloroformate. A C-18

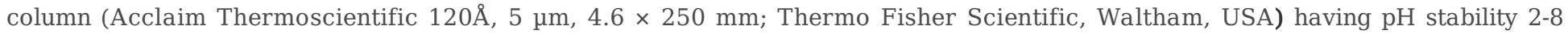
was used for chromatographic separation. Analysis was performed using $20 \mathrm{mmol} / \mathrm{L}$ phosphate (potassium) buffer (pH 6.5) as solvent A and 45/40/15 acetonitrile/methanol/water as solvent B. The separation was obtained at a flow rate of $1 \mathrm{ml} / \mathrm{min}$ using a gradient elution that allowed $0 \% \mathrm{~B}$ at $0.01^{\text {st }} \mathrm{min}$, followed by linear raise of eluent B to $50 \%$ at $41^{\text {st }}$ min and then decreased to $0 \%$ at $43^{\text {rd }}$ min. The temperature of the column oven was set at $40^{\circ} \mathrm{C}$ and injection volume to $1 \mu \mathrm{L}$. Resolution monitoring of amino acid derivatives were performed through fluorescence detector with excitation and emission set at $330 \mathrm{~nm}$ and $450 \mathrm{~nm}$ respectively. Labsolutions LC/GC (Shimadzu, Kyoto, Japan) was used as a working station. The amino acid standard mixture was prepared by mixing eighteen amino acids (SRL, Mumbai, India) in $0.1 \mathrm{~N} \mathrm{HCl}$ which included Aspartic acid (Asp), Glutamic acid (Glu), Serine (Ser), Glycine (Gly), threonine (Thr), Histidine (His), Alanine (Ala), Arginine (Arg), Tyrosine (Tyr), Valine (Val), Methionine (Met), Cystine (Cys), Phenylalanine (Phe), Tryptophan (Trp), Isoleucine (Ile), Leucine (Leu), Lysine (Lys) and Proline (Pro). The amino acid comparison of standard mixture and digested sample was done on the basis of retention time as well as for area under the peak for detection and quantification of each eluted amino acids.

$$
\operatorname{AAS}(\%)=\frac{\text { Amino acid in test protein }(\mathrm{g})}{\text { Amino Acid in refrence protein }(\mathrm{g})} \times 100
$$

Amino Acid Score (AAS). The Recommended Dietary Allowances (RDA) of amino acid for children (Age: 6 months to 3 years) was used as reference protein for the calculation of amino acid score of each cereal.

Scanning Electron Microscopy (SEM) and Energy Dispersive X-Ray Analyzer (EDX). The morphology of the isolated freeze-dried prolamin powder was studied with Carl Zeiss Supra-55 SEM (Carl Zeiss, Oberkochen, Germany) at an accelerating voltage of 10-15 $\mathrm{kV}$. The samples were mounted on stubs using double-sided adhesive tape. Prior to SEM imaging, all samples were sputter-coated with gold for 2 min by Quorum Sputtered Coater (Q150R ES, Laughton, East Sussex, UK). Further, the elemental composition was analysed with Energy dispersive X-ray spectrometer (Oxford Instruments Nano Analysis \& Asylum Research, High Wycombe, UK).

Transmission Electron Microscopy (TEM). The structures of different Prolamin were investigated using Transmission Electron Microscope (JEM-2100, JEOL TEM, Tokyo, Japan). The samples (1mg/ml) were prepared in 50\% acetonitrile containing $0.1 \%$ formic acid solvent and a drop of the diluted protein suspension solutions (15 $\mu$ l) was poured on a polycarbon film supported on a copper grid and dried at ambient temperature. The samples were examined on TEM at an accelerating voltage of $200 \mathrm{kV}$. The sizes of the protein nano-structures were obtained using iTEM software (Olympus, Münster, Germany). The radius of the diffraction rings in SAED pattern is the inverse of the d-spacing of the associated lattice planes and radii of the rings were determined using iTEM software.

X-ray Diffraction (XRD). XRD studies, in the $2 \theta$ (Bragg's angle) range of $10-60^{\circ}$ were performed using X-ray diffractometer (Shimadzu 7000, Shimadzu Corporation, Kyoto, Japan) in Bragg-Brentano geometry with Cu $\mathrm{K}_{\alpha}$ radiation ( $\lambda=1.5405 \mathrm{~A}^{0}$ ). Some of the prolamins were found to be nano-crystalline in nature i.e. these are composed of crystallites or grains that are the ordered building blocks units repeated periodically and separated by disordered grain boundaries. Debye-Scherrer equation was used to calculate the particle crystallite size on corresponding diffraction pattern based on the dimension of full-width at half-maximum (FWHM) values.

$$
D=\frac{K \lambda}{\beta \cdot \cos \theta}
$$

Where, $\mathrm{D}$ is the mean size of the ordered (crystalline) domains, $\lambda$ is the X-ray wavelength in nanometre (nm), $\beta$ is the peak width of the diffraction peak profile at half of the maximum height (FWHM) in radians, $\theta$ is the Bragg angle, which can be in degrees or radians, $\cos \theta$ corresponds to the same number and $K$ is a constant related to crystallite shape, normally it can be taken as 0.89 or 0.9 for Full Width Half Maximum (FWHM) of spherical crystals with cubic unit cells 17.

Further, inter-planar spacing (d), was calculated from the peak positions using Bragg's equation

$$
2 \mathrm{~d} \sin \theta=\mathrm{n} \lambda
$$


Where $\mathrm{d}$ is inter-planar spacing, $\mathrm{n}$ is order of diffraction.

Statistical analysis. The results were expressed as a mean \pm SD and compared statistically at $p \leq 0.05$, using one-way analysis of variance (ANOVA) with Tukey's post hoc test (Version 17, Minitab Inc., State College, USA).

\section{Result And Discussion}

The wheat, rye and barley flours were extracted to isolate the prolamins using ${ }^{11}$ protocol. The cream-coloured gliadin, hordein and secalin were obtained on freeze drying the protein isolates (Fig. 1).

Physiochemical characteristics. The protein content (PC) of the prolamin extracted from wheat, rye and barley followed a decreasing order as gliadin (64.94 - 70.26\%), secalin (47.50 - 60.70\%) and hordein (34.06 - $45.17 \%)$ respectively (Table S1). Among the cultivars, the gliadin from HPW-349 contained the highest PC while hordein from BH-959 contained the lowest PC. The PC of prolamins was found to vary significantly ( $\mathrm{p} \leq 0.05)$. DuPont et al., ${ }^{11}$ reported the protein content of extracted gliadin (40.1\%) slightly lowered than our findings might be due to varietal difference and/ or small-scale extraction process of gliadin.

The water activity $\left(a_{w}\right)$ of the freeze dried prolamin was observed to vary from 0.66 to 0.82 , with the highest value in secalin from MCTLG-2 and the lowest value in hordein from $\mathrm{BH}-902$. These $\mathrm{a}_{\mathrm{w}}$ values of prolamin indicates the microbial and physiochemical stability, which consequently influences the texture, rehydration and structural properties. The values of $a_{w}$ showed a significant $(p \leq 0.05)$ difference among the cultivars. Variation in the protein content of prolamins may be attributed to the variation of amino acid composition, cereal genetic diversity, fertilizer application and agricultural practices.

The color characteristics of the prolamins are explained via CIE color values which have been recorded in terms of $L^{*}, a^{*}, b^{*}, H_{u e}$ angle $\left(H^{\circ}\right)$ and Chroma $\left(C^{\star}\right)$ values. $L^{*}$ value indicates the lightness of the extracted prolamin which was found to be in the range 53.13-68.12 (Table S1). In the investigated cereals, the $L^{*}$ value for hordein from BH-902 was found to be significantly $(p \leq 0.05)$ higher while for secalin from MCTLG-1 lies on lower side. The dark color (lower $L^{*}$ value) of the secalin might be due to the presence of pigment and oxidative changes as compared to hordein and gliadin. In case of coordinates $a^{*}$ and $b^{\star}$, the observed positive values for prolamin falls in the range $0.53-2.06$ and $6.90-13.93$ which implies color had red and yellow tinge respectively. For the investigated cultivars, the $a^{*}$ value was found to be the highest for gliadin $(1.53-2.06)$ and the lowest for hordein (0.53 - 1.28$)$. On the other hand, the high $b^{*}$ values for gliadin $(9.68$ - 13.93) reflects more yellow tint in comparison to secalin $(6.90-10.13)$ and hordein $(7.41-9.61)$. On the whole, a significant $(p \leq 0.05)$ difference in $a^{*}$ and $b *$ values were observed among the prolamins at inter as well as at intra-cultivars levels.

Hue angle $\left(\mathrm{H}^{\circ}\right)$ of the extracted prolamin was found to lie in the range $78.51-86.85^{\circ}$ for different cultivars. This angle represents the color variants on the colour wheel, $90^{\circ}$ represent yellow colour, therefore the colour of prolamins is more towards yellowish tinge. In the present study, a small difference was observed in hue angle among the prolamin. However, the $\mathrm{H}^{\circ}$ was found to be the highest for hordein from $\mathrm{BH}-959$ and the lowest for secalin from MCTLG-5. The chroma values $\left(C^{\star}\right)$ of the investigated cereals were found to vary significantly $(p \leq 0.05)$ from $6.95-14.05$, which represents the intensity of particular color. The higher $C^{*}$ value, in case of gliadin $(9.84-14.05)$ indicates a profound tinge of its intrinsic color as compared to both secalin (6.95 10.33) and hordein $(7.46-9.63)$. The analysis of data revealed that the $C^{\star}$ values of different cereals prolamin varied significantly $(p \leq 0.05)$ at inter and intra-cultivar levels except for hordein where the difference was non-significant $(p \geq 0.05)$.

Amino Acid Composition. The amino acid composition of extracted prolamin from wheat, rye and barley cultivars is presented in Table 1 \& S2 and Fig. 2 \& S1. Among EAA, the foremost amino acids were found to be isoleucine and phenylalanine which constituted about $6.26-8.81 \%$, and $5.58-7.22 \%$ respectively for different prolamins. Other EAA were histidine (1.38-4.02\%), threonine (1.28 - 4.22 \%), lysine (0.23 - $3.53 \%)$, tryptophan (1.74 - $3.05 \%)$, leucine $(0.16-2.94 \%)$, and methionine $(0.82-1.62 \%)$. Histidine (His), threonine (Thr), valine (Val), leucine (Leu) and lysine (Lys) contents were observed to vary significantly $(\mathrm{p} \leq 0.05)$ while phenylalanine (Phe), isoleucine (lleu), methionine (Met) and tryptophan (Trp) varied non-significantly ( $\mathrm{p} \geq 0.05)$ among different cereal and within their respective cultivars.

The amount of His was found to be higher in gliadin (2.34 - $4.02 \%)$, followed by hordein (1.45 - $2.35 \%)$ and secalin (1.38 - $2.24 \%)$. This implies that gliadin has high propensity towards stabilizing the insoluble proteins through $\pi-\pi$ or $\pi$-cation interactions with aromatic groups than hordein and secalin 18. However, Thr, Val, Lys content was high in hordein (Thr 3.89 - 4.22 \%; Val 4.73 - 5.34 \%; Lys $2.55-3.53 \%$ ) and secalin (Thr $2.27-3.63 \%$; Val 3.41 $4.92 \%$; Lys $1.28-2.49 \%$ ) while low in gliadin (Thr $1.28-2.59 \%$; Val $0.42-0.97 \%$; Lys $0.22-0.86 \%$ ). Hordein and secalin contain higher amount of Ileu, Val and Leu which are mostly found in hydrophobic core and thus promote the folding process of protein more favourably than gliadin ${ }^{18}$. $\beta$-branched residues such as Thr, Val, lleu are inclined to form $\beta$-sheet configuration, while linear chain residues such as Ala, Leu, Lys, Met, Glu have more propensity towards a-helix configurations ${ }^{19}$. The total essential amino acids (TEAA) were higher in hordein (30.97 - $\left.32.97 \%\right)$ and secalin (27.75 - $\left.33.28 \%\right)$ while lower in gliadin $(24.49-27.07 \%)$. It is noted that limiting EAA Lys influences more to TEAA content.

Present results are in close proximity with the work conducted by ${ }^{12}$, who studied the amino acid content of prolamin from wheat, rye and barley except for slightly lower value of phenylalanine $(0.92-1.65 \%)$, lysine $(0.25-1.36 \%)$ while higher value of leucine $(3.89-5.27 \%)$. Wang \& Chen ${ }^{20}$ reported similar observations on TEAA of gliadin and hordein except for slightly lower content of Lys and lleu compared to our results. Interestingly, Trp gets destroyed by acid hydrolysis by traditional oven method ${ }^{15}$, although our results showed its presence which may be due to presence of thiol group ( $\beta$-mercaptoethanol) and relatively mild conditions than traditional oven method ${ }^{21}$. The moist heat, under controlled pressure and relatively short duration could have prevented Trp destruction compared to dry harsh oven method. 
The non-essential amino acids (NEAA) are known to stabilize the protein polymeric structure through covalent, non-covalent, hydrophobic, electrostatic and van der waal interactions (Table S2, Fig. S1). Glutamic acid was found to be the predominant NEAA with a mean value of 22.35 - 38.18 \% followed by proline (5.91 - 12.22 \%). The amount of Glu was $33.76-38.18 \%$ in gliadin, $30.52-37.21 \%$ in secalin and $22.35-24.78 \%$ in hordein. A similar trend was obtained for Pro content in gliadin (9.51 - 12.22 \%), secalin (6.19- $7.74 \%)$ and hordein (5.91 - $7.67 \%)$. Experimentally the highest value of glutamic acid was observed in wheat cultivar HPW-2492 (38.18\%) and the lowest in barley cultivar BH-902 (22.35\%), whereas the highest amount of Pro was found in gliadin from HPW-155 (12.22 \%) and the lowest in hordein from BH-959 (5.91 \%). This implies that the protein structure of gliadin is hypothesised to have more $\mathrm{H}$-bonding due to active participation of Glu. However Pro lacks $\mathrm{H}$-donor atom in its structure on a-amino group. Other NEAA were arginine (2.95 - 9.99\%), alanine (3.48 - $7.59 \%)$, aspartic acid (4.30 - $7.88 \%)$, serine (4.64 - $7.61 \%)$, glycine (2.45 - $6.34 \%)$, tyrosine $(1.33-5.19 \%)$ and cysteine $(0.56-2.38 \%)$. The NEAA of prolamin observed to vary significantly $(\mathrm{p} \leq 0.05)$ among different inter and intra cultivar levels excluding cysteine and alanine.

Cys was found to be higher in secalin (1.65 - $2.38 \%)$, followed by hordein (1.75 - $1.97 \%)$ and gliadin $(0.56-0.94 \%)$, this implies that intramolecular disulphide interaction might follow the respective order. Gly was found to be the highest in hordein (5.41 - $6.34 \%)$, followed by secalin ( 2.45 $4.54 \%)$ and gliadin $(2.45-3.50 \%)$, whereas Ala was found to be the highest in gliadin $(6.68-7.59 \%)$, followed by hordein (4.23 - $4.78 \%)$ and secalin $(3.48-3.97 \%)$. This implies that gliadin structure is more ordered and stabilized to compact configuration while hordein structure was speculated to be less ordered structure to random coiled configuration. The ordered structure of protein was strengthened by Ala and Glu (a-helix former) while weaken by Pro and Gly (a-helix breaker or $\beta$-sheet breaker) ${ }^{22}$. The Tyr residue was found to be higher in hordein (3.39 - $\left.5.19 \%\right)$ followed by gliadin ( $\left.2.71-3.56 \%\right)$ and secalin (1.33 - 2.97\%), whereas Arg content was found to be the lowest in gliadin (2.95 - 3.62 \%) while comparable in secalin (5.84 - $7.74 \%)$ and hordein (6.36 - $7.12 \%)$. This means that in Tyr-Tyr covalent interactions, the secalin was comparatively less active than hordein and gliadin. Hou et al., 18 suggested that the insolubilizing interactions has been facilitated by Asp, Glu, Arg and aromatic residues (Phe, Tyr, Trp, His). The role of Tyr-Tyr bond in stabilizing the toxic repetitive moiety of 33-mer gliadin was reported by ${ }^{23}$. The Tyr phenolic group participates in formation of oxidative radical and thus stabilizes the intermediate proteins through the covalent bond of di-tyrosine.

Total non-essential amino acid (TNEAA) comprises of $66.72-75.51 \%$ of the total amino acid and being the highest in gliadin from HPW-249 and the lowest from secalin from MCTLG-3. The higher TNEAA of gliadin (72.93 - 75.51\%) and secalin (66.72 - $72.25 \%)$ speculated to have more compact and stabilized protein-protein interaction as compared to hordein $(67.03-69.03 \%)$. The role of NEAA is well known in stabilizing protein tertiary structure and provides flexibility and strength to the dough.

The NEAA profile obtained in present investigation is consistent with the literature values. Similar results were reported by ${ }^{12}$ for gliadin, secalin and hordein except for slightly lower amount of Asp (1.30 - $2.79 \%)$ and $\operatorname{Arg}(1.83-2.34 \%)$. Similarly, the amount of NEAA in gliadin and hordein reported by ${ }^{20}$ showed the similar findings except lower value of aspartic acid (1.3 - $\left.2.9 \%\right)$ and arginine $(2.4-2.7 \%)$ while higher value of proline (15.0 - $\left.21.2 \%\right)$ content. The work of ${ }^{24}$ on amino acid composition of barley hordein reported the similar findings except for slightly lower value of isoleucine (3.48 - 4.63 $\%)$ and higher value for proline (11.73 - $16.93 \%)$. Field et al., ${ }^{12}$ reported more serine and threonine in hordein than gliadin and secalin which are similar to our finding, while ala was high in gliadin and secalin than hordein. However, our findings show higher content of ala in gliadin and relatively comparable in secalin and hordein. Gellrich et al., ${ }^{25}$ analysed secalin for amino acid and reported similar results except lower value for Arg, Lys and higher content of pro (20.4\%) in comparison to current findings. The variation in the amino acid profile in extracted prolamin with the previous findings might be due to influence of extraction procedure and to some extent varietal differences.

The amino acid score (AAS) of prolamin (Table S2), indicates the superiority of protein corresponding to reference protein ${ }^{26}$. The AAS determined was found to be higher in hordein (92.02 - $97.97 \%)$ followed by secalin (82.48 - $98.91 \%)$ while lower in gliadin (72.77 - $80.46 \%)$. It implies that the protein profile of secalin and hordein was relatively superior to gliadin. Similarly many authors reveals the higher biological value and superiority of rye and barley protein ${ }^{27,28}$. The AAS of the prolamin of rye cultivar MCTLG-3 (98.91\%) was the highest whereas gliadin of wheat cultivar HPW-249 (72.77\%) received the lowest score. Lysine, methionine and leucine contents of the extracted prolamin were found below the reference protein ${ }^{26}$. Similar results have been reported by ${ }^{24}$ for spring barley cultivar which contained underneath levels of lysine and methionine in comparison to reference protein.

The International ImMunoGeneTics (IMGT) system of information categories the amino acids into three 'hydropathy' groups (Table 1) namely hydrophilic (Lys, Arg, Glu and Asp), hydrophobic (Phe, Trp, lleu, Leu, Met, Cys, Ala, and Val) and neutral (Tyr, Pro, Gly, Thr, Ser and His) ${ }^{29}$. Out of total amino acids, the hydrophilic amino acids group constituted about $47.35-52.10 \%$ in secalin, $45.31-50.02 \%$ in gliadin, and $43.22-46.34 \%$ in hordein. This implies that secalin contains more amount of soluble protein while hordein contains the least. The highest hydrophilic amino acids content was registered by secalin from MCTLG-5 and the lowest by hordein from BH-393 cultivar. The hydrophilic amino acids of prolamin were further sub categorized into basic and acidic amino acids, which accounts for $6.16-15.08 \%$ and $30.23-43.65 \%$ respectively. The acidic AA residues were high in gliadin (39.15 - $43.65 \%)$ and low in hordein (30.23 - $31.74 \%)$ whereas basic AA residues were high in hordein (11.48 - 15.08 \%) and low in gliadin (6.16 - $8.42 \%)$. This implies that gliadin has relatively higher solubility than secalin and hordein, due to higher content of acidic AA residues. This fact is confirmed by the findings of ${ }^{18}$, that Asp/Glu acid residues promotes the protein solubility through the formation of salt bridges by electrostatic interaction of Lys-Asp, Lys-Glu, Arg-Glu and Arg-Asp. On the other hand, acidic AA favours protein insolubility and aggregation when participate in anion- $\pi$ interaction with aromatic residues. Acidic and basic amino acid fractions of extracted prolamin have shown a significant $(p \leq 0.05)$ difference among intra and inter cultivars levels.

The hydrophobic AA constituted $26.89-30.86 \%$ and comprised of aliphatic, S-containing and some aromatic amino acids which accounted for 16.30 $18.90 \%, 1.52-3.39 \%$ and $7.35-10.04 \%$ respectively. The S-containing amino acids found to be higher in secalin (2.97 - $3.39 \%)$ and hordein (2.79 - 
$3.30 \%)$ while lower in gliadin $(1.52-2.18 \%)$. This implies that, due to greater potential for covalent interaction, secalin achieves more symmetry in its protein structure. The S-containing amino acids content of secalin from MCTLG-3 and gliadin from HPW-155 were the highest and the lowest respectively.

The total neutral amino acids of prolamin varied from $19.91-28.55 \%$ and constituted of non-polar, polar and aromatic amino acids which accounted for $8.70-15.73 \%, 6.46-10.44 \%$ and $1.33-5.19 \%$ respectively. The decreasing trend in polar AA found to be higher in hordein (8.60 - $10.44 \%)$ followed by secalin $(8.95-9.88 \%)$ and gliadin $(6.63-7.64 \%)$, while in non-polar group the decreasing trend follows as higher in gliadin (12.08 - $15.73 \%)$, followed by hordein $(11.32-14.01 \%)$ and secalin $(8.70-12.28 \%)$. This implies that the higher content of polar AA residues in hordein and secalin have great propensity towards solubility of proteins than gliadin, while gliadin was noticed to have higher relative proportion of non-polar AA which actively take part in protein stability and reduces the solubility of protein. Hordein from BH-393 and gliadin from HPW- 147 accounted for the highest and the lowest content of polar amino acids respectively. However, the neutral aromatic group of amino acid was found to be highest in BH-959 and lowest in MCTLG5 secalin. This implies that Tyr-Tyr covalent interactions speculated to be more in hordein which attributed to greater aggregation tendency than gliadin and secalin 23 .

The polar, neutral aromatic and s-containing group of amino acids observed to varied significantly ( $\leq \leq 0.05)$ whereas aliphatic, non-polar, hydrophobic aromatic, total hydrophobic, total hydrophilic and total neutral amino acids varied non-significantly $(p \geq 0.05)$ among different extracted prolamin at inter and intra cultivar level. The variation in amino acid composition is considerably affected by irrigation practices, fertilizer application, agro-climatic conditions, and genotype.

Polypeptide characteristics. The gliadin, secalin and hordein were analysed for their electrophoretic pattern on SDS-PAGE (Fig. 3). The electrograms were categorized broadly into storage protein and metabolically active protein. Schalk et al., ${ }^{16}$ sub-categorized the prolamins as HMW-GS, $\omega$-gliadin, LMW-GS, $\mathrm{a} / \beta$-gliadin and $\gamma$-gliadin in wheat cultivars; D-hordein, C-hordein and $\gamma / B$-hordein in barley cultivars and HMW-secalin, 75K secalin, $\omega$-secalin and 40K secalin in rye cultivars. Additionally, Lexhaller et al., ${ }^{30}$ broadly grouped the gliadin, secalin and hordein into high molecular weight (HMW), medium molecular weight (MMW) and low molecular weight (LMW) peptides groups on the basis of molecular weight, amino acid characteristics (sequence and composition) and their participation in band formation.

The total polypeptide bands ranged from 20-22 in wheat cultivars, $15-16$ in rye cultivars and 23-25 in barley cultivars. The HMW group covers $2-4$ peptides of 74.63-109.08 kDa in wheat cultivars, 2 peptides of $91.80-110.68 \mathrm{kDa}$ in rye cultivars and 2 peptides of $72.74-97.26 \mathrm{kDa}$ in barley cultivars respectively. Densitometric analysis (Table S3) showed the relative proportion of HMW group accounted to $1.43-8.34 \%$ and varied non-significantly $(p \geq 0.05)$ among gliadin and secalin at inter and intra cultivar levels, whereas in hordein a significant difference $(p \leq 0.05)$ was observed in inter and intra cultivar levels. Anjum et al., ${ }^{31}$ reported similar findings that wheat contained 3-5 HMW-GS subunits, while ${ }^{32}$ revealed the presence of $1-5$ HMW secalin subunits with the relative proportion of HMW group between $6.67-10.86 \%$ which supports our findings. The HMW group of prolamin is characterized by large amount of glutamine, glycine and proline amino acid ${ }^{33}$. The elasticity and flexibility of polypeptide chain is primarily governed by HMW group due to presence of cystine (involving disulphide linked aggregates) and glycine confers the greater conformational space in reference to its bond angle. HMWgroup is accountable for unique dough elastic property which is favourable for superior baking performance ${ }^{34,35}$.

Medium molecular weight (MMW) group comprises of sulphur poor $\omega$-prolamin monomers with MW around 40-50 kDa except wheat gliadin which also includes $\mathrm{MW}$ of $60-68 \mathrm{kDa}^{30}$. The $\omega$-gliadin was distinguished into 5 peptides in region between $43.90-68.06 \mathrm{kDa}$ in wheat cultivars, while in barley cultivars 4-5 peptide of C-hordein in MW range of 40.05-60.09 kDa and rye cultivars had 3 peptides of $\omega$-secalin in the MW range of $37.22-40.98 \mathrm{kDa}$. The relative proportion of MMW group (Table S3), ranged between $6.32-28.77 \%$ of total extracted prolamin. The $\omega$-gliadin (20.74 - $28.73 \%$ ); C-hordein (13.43 - $23.40 \%$ (except in $\mathrm{BH}-959$ with $28.77 \%$ ) and $\omega$-secalin $(6.32-8.68 \%$ ) had MMW group of prolamins in decreasing order. The highest relative proportion of MMW group among different cereal extracted prolamin was shown in hordein from BH-959 (28.77\%) while the lowest was observed in secalin from MCTLG-5 (6.32\%). A significant ( $\mathrm{p} \leq 0.05)$ difference was observed among different extracted prolamins. MMW group predominantly contains glutamic acid, proline and phenylalanine, which is relatively richer in polar and acidic amino acids while lower in basic amino acids. Therefore, MMW group had less surface hydrophobicity than LMW group ${ }^{36,37}$. The distinctive feature of MMW group of protein is the absence of cysteine amino acid residues which are usually involved in disulphide bonding among proteins in three dimensional gluten network ${ }^{38}$. MMW group mainly occupies the central domain of prolamin which mainly consists of repetitive motifs of glutamine, prolamin and phenylalanine, which tends to form extended non-compact structures due to lack of cysteine and acquires random coiled $\beta$-turn configuration 36,39 .

According to ${ }^{30}$, the LMW group covers the monomeric peptides (identified as $\alpha / \beta$-gliadins, $\gamma$-gliadins in wheat; $\gamma$ - $40 \mathrm{k}$-secalins in rye and $\gamma$-hordeins in barley) and polymeric peptide (recognized as LMW-GS in wheat, $\mathrm{Y}$-75k-secalins in rye and B-hordeins in barley). The LMW peptides ranged from $28-35$ $\mathrm{kDa}$ except in $\mathrm{Y}-75 \mathrm{k}$-secalins ( $\mathrm{MW} 50 \mathrm{kDa}$ ). This group of prolamin is sulphur rich due to presence of cysteine in hydrophobic part of $\mathrm{C}$-terminal domain, while $\mathrm{N}$-terminal domain have glutamine, proline and aromatic (especially phenylalanine, tyrosine) amino acid residues ${ }^{33}$. It leads to a compact globular structure due to formation of intra-molecular covalent disulphide bridge between two cysteine molecules by oxidation of its thiol group. Therefore, threedimensional structure of protein usually contains helical and beta sheet configuration by active participation of hydrophobic interactions which provides characteristic viscous property and extensibility to dough and improve bread loaf volume ${ }^{36}$.

The LMW group in wheat cultivars comprises of a/ $\beta$-gliadins, $Y$-gliadins together with LMW-GS, distributed in MW range between $26.25-43.30 \mathrm{kDa}$, while Y/B-hordein dispersed over 26.14-39.91 kDa MW in barley. The secalin consists with $\mathrm{Y}-40 \mathrm{k}$-secalins and $\mathrm{Y}$-75k-secalins with MW ranges between $26.67-$ $32.35 \mathrm{kDa}$ and $50.27-62.37 \mathrm{kDa}$ respectively in this region. The relative proportion of LMW group, ranged from $12.80-45.86 \%$ of extracted prolamin with higher amount in rye, followed by wheat and barley as elaborated in Table S3. Petrovičová et al., ${ }^{32}$ reported slightly higher values for LMW group of secalin 
than present study. The highest relative proportion of LMW group was revealed in secalin from MCTLG-3 (45.86 \%) and the lowest in hordein from BH-946 (12.18\%). The LMW group of rye secalin comprises of $y$-75k-secalins and $y$-40k-secalins with relative proportion of $26.53-31.96 \%$ and $13.39-14.82 \%$ respectively. The $\mathrm{Y}-75 \mathrm{k}$-secalins were obtained in high concentration in rye cultivar MCTLG-3 and in low concentration in rye cultivar MCTLG-5 whereas the highest concentration of $\mathrm{Y}$-40k-secalins was attained in rye cultivar MCTLG-2 and the lowest in MCTLG-1.

Schalk et al., ${ }^{16}$ reported 80-120 kDa for HMW group, 43-68 kDa for MMW group and 32-45 kDa for LMW group of gliadins, whereas 100 kDa for Dhordein, 45-65 kDa for C-hordein and 32-40 kDa for B-hordein. Socha et al., ${ }^{40}$ showed the MW of 30-45 kDa for $\mathrm{a} / \beta$, $\mathrm{\gamma}$-gliadins in wheat while, $37 \mathrm{kDa}$ for $40 \mathrm{k}-\gamma$-secalins and $66.2 \mathrm{kDa}$ for $75 \mathrm{k}$ - - -secalins in rye flours respectively. Field et al., ${ }^{12}$ also reported the MW of $40 \mathrm{k}-\gamma$-secalins and $75 \mathrm{k}-\gamma$-secalins as $33 \mathrm{kDa}$ and $54 \mathrm{kDa}$ respectively, while ${ }^{41}$ also reported the MW of secalin as $35 \mathrm{kDa}$ and $66 \mathrm{kDa}$, which confirms our findings. The slight variation in MW among present study with that of previously studied MW might be influenced by genetic makeup, agro-climatic differences and protocol employed for extraction of prolamin.

The extracted prolamin via DuPont extracted protocol were found to be contaminated with metabolic active protein having molecular weight ranges between 9.30-24.19 kDa, 6.50-23.93 kDa and 7.21-25.38 kDa for gliadin, secalin and hordein respectively. Densitometric evaluation (Table S3) reveals the relative proportion of ALB+GLO group were varied between $38.13-69.10 \%$ wherein a more diversity has been observed in hordein (38.13 - $69.10 \%$ ), followed by secalin (43.51 - $51.93 \%$ ) and least in gliadin (45.00 - 53.59\%). A significant difference was observed in ALB+GLO group including intracultivar differences. Petrovičová et al., ${ }^{32}$ reported that the relative share of ALB+GLO was estimated to be $20.97-31.02 \%$ of total protein from rye cultivars which is slightly less than our findings. The variation in the relative proportion in ALB+GLO between present studies and reported values in the literature might be due to different extraction procedure employed.

Genetic proximity of various accessions in the present study was further evaluated through Jaccard Similarity Matrix by means of Unweighted Pair Group Method with Arithmetic Averages (UPGMA) to construct a dendrogram (Fig. S2). Three distinct groups could be identified from the dendrogram of gliadin, secalin and hordein, moreover, gliadin and hordein were closer to each other than secalin. In case of wheat gliadin, group-I had two accessions where HPW-42 was found to be dissimilar from rest of the other extracted gliadins with similarity coefficient of 0.58; Group-II had two accessions of closely resembled cluster of HPW-147, HPW-155, HPW-236 and HPW-249, HPW-349 with similarity coefficient of 0.76; while Group-III had further two accessions of closely resembled cluster of HPW-147, HPW-155 with similarity coefficient of 0.85 and other HPW-236 with 0.75 similarity coefficient. On the other hand, hordein had three accessions where $\mathrm{BH}-902$ and $\mathrm{BH}-393$ was observed to be closely resembled with similarity coefficient of 0.82 while, $\mathrm{BH}-959$ and $\mathrm{BH}-946$ are dissimilar from rest of the other with similarity coefficient of 0.70 and 0.74 respectively. Unlike closely resembled gliadin and hordein, the rye secalin was distinguished into two accessions with closely resembled clusters of MCTLG-4, MCTLG- 5 with similarity coefficient of 0.78 while another cluster of MCTLG-2, MCTLG-3 and MCTLG-1 where MCTLG-2 and MCTLG-3 shared similarity index of 0.88 .

This variation among cereals might be due to dissimilarity in genotypic diversity, inherent surface amino acid profile, interaction with extraction solvents as well as protocols working conditions.

Particle Characteristics. The prolamins exist as three-dimension structured particle. This microstructure was analysed using sophisticated instruments to elucidate its properties.

Dynamic Light Scattering (DLS). The prolamins were analysed for particle size distribution (PSD) in terms of polydispersity index (PDI) and hydrodynamic diameter $\left(D_{h}\right)$ in solution as presented in Table 2, Fig. S3. PDI values for prolamins fall in the range 0.49 Wang, Y. \& Chen 0.87. Lower PDI value i.e. less than 0.5 indicates more uniform PSD and existence of monodisperse system ${ }^{42}$. In the present study, PDI of the secalin ( $\left.0.66-0.87\right)$, hordein (0.58 - 0.83 ) and gliadin $(0.49-0.64)$ were higher indicating disparity in particle size.

The gliadin and hordein mainly existed in monomeric form with hydrodynamic diameter $\left(D_{h}\right)$ in the ranges between $1.23-1.83 \mathrm{~nm}$ and $6.67-7.62 \mathrm{~nm}$ respectively. The hordein from BH-946 (7.62 nm) had higher and gliadin from HPW-42 (1.23nm) had lower hydrodynamic diameter. Gliadin showed monomeric units nonetheless hordein shows the existence of some higher ordered aggregates. This fact is also supported by amino acid composition that the higher proportion of basic AA and S-containing AA residues in hordein shows its tendency in formation of aggregates through strong electrostatic and hydrostatic interaction ${ }^{9}$.

The secalin showed a bimodal PSD with two populations in the solution. The particle size of small and large sized population varied from 7.73 $18.44 \mathrm{~nm}$ and $26.48-68.33 \mathrm{~nm}$, whereas, their proportion varied from $99.60-99.90 \%$ and $0.10-0.40 \%$ respectively. It indicated that the small sized particles were abundant in number while large sized particle were scanty. The large sized particles were observed in secalin from MCTLG-3 (18.44 nm; $68.33 \mathrm{~nm}$ ) and the small sized from MCTLG-4 of $7.73 \mathrm{~nm} ; 26.48 \mathrm{~nm}$ in peak 1 and 2 respectively. The PDI and $\mathrm{D}_{\mathrm{h}}$ of the investigated prolamin have been found to vary significantly $(p \leq 0.05)$ among different extracted prolamin samples including intra-cultivar differences except wheat cultivars which shares non-significant differences $(p \geq 0.05)$.

The zeta potential (ZP) profile of the gliadin, secalin and hordein have shown a positive value in the range of 23.53-27.00 $\mathrm{mV}, 11.23-16.60 \mathrm{mV}$ and $4.10-$ $7.98 \mathrm{mV}$ respectively. The ZP values were found to be significantly $(\mathrm{p} \leq 0.05)$ different at inter as well as intra-cultivar levels. The relatively higher zeta potential values of gliadin indicate the high stability of their monomeric protein subunits. Gliadin and hordein had a monomodal while secalin had a bimodal PSD. The secalin had relatively lower ZP than gliadin which might be due to its bimodal PSD and large particle size of the minor component. On the other hand, the substantially lower ZP values for hordein reflected the greater tendency of protein motifs to aggregates due to lower surface charge. The constituent protein units predominantly exist in higher ordered form in secalin and hordein compared to gliadin, which was correlated by PDI value. 
The low ZP in case of hordein is probably due to its high basic amino acid contents which might be involved in $\pi$-interaction and increase aggregation propensities $^{18}$.

Zavareze et al., ${ }^{43}$ has reported that zeta-potential of gliadin was about $30 \mathrm{mV}$ and had remarkable colloidal stability. However, gliadin nano-particles prepared by controlled aggregation had $\mathrm{D}_{\mathrm{h}}$, PDI and ZP of $190-220.6 \mathrm{~nm}, 0.067-0.232$ and $14.8-18.3 \mathrm{mV}$ respectively ${ }^{44}$. Peng et al., ${ }^{45}$ has also demonstrated the high zeta potential which indicated greater electrostatic repulsions among the protein molecules and poses higher electrostatic barrier which prevents protein aggregation. The overall zeta-potential of gliadin, secalin and hordein was observed to be in decreasing order. It further indicated the solution stability of these proteins was also in the same order. The higher colloidal stability of gliadin suspension is attributed to the high glutamine content which is engaged in hydrogen bonding with water ${ }^{46}$. The variation in zeta potential between inter and intra cultivar of present and earlier studies might be due to difference of dispersion media, amino acid side chains, $\mathrm{pH}$, ionic strength of solution and temperature during extraction/analysis process 43,46 .

SEM and EDX. Scanning Electron Microscopy (SEM) and Energy Dispersive X-Ray Analyzer (EDX) were used to investigate the morphology and elemental composition of prolamin respectively as elucidated in Fig. 4 and Table S4. Morphology by SEM illustrated the globular particle arrangement of gliadin while sheet-like and stacked flaky structure was observed for secalin and hordein respectively. Similar globular particle arrangement has been reported in gliadin nanoparticles ${ }^{5}$ which seems consistent with our findings. Due to irregular pattern found in SEM images of gliadin, the size of observed morphology could not be quantified.

EDX analysis is an extended application of SEM technology which reveals the element composition of matter. The EDX analysis revealed the major elements present in the prolamin as C (52.33 - 57.60 \%), O (27.03 - 35.26 \%) and N (10.43 - $14.20 \%)$, while minor elements as S (0.12 - $0.26 \%)$, P (0.37 $-0.61 \%), \mathrm{Na}(0.28-0.75 \%)$ and I $(0.25-0.54 \%)$ expressed in atomic percentage. Similarly, the EDX analysis expressed in weight percentage showed the major elements as C (43.16 - 50.71\%), O (30.99 - 38.94\%) and N (9.46 - 14.80\%), while minor elements as S (0.25 - $0.63 \%), \mathrm{P}(0.84-1.31 \%), \mathrm{Na}$ $(0.42-1.18 \%)$ and I $(1.97-4.56 \%)$. The EDX analysis suggests that the peptide of gliadin consist of C, N, O with traces of S and P while the source of $\mathrm{Na}$ and I detected was possibly due to Nal salt used in the preparation. This implies that the relative ratio of C:O:N:S (weight percentage) in prolamin followed the ascending order, being higher in hordein (113:156:43:1), followed by secalin (110:76:21:1) and gliadin (77:48:24:1). It is noted that 0 is two times the amount of $\mathrm{N}$ in gliadin while 3.6 times in secalin and hordein.

X-Ray Diffraction. XRD is the primary and most widely employed technique to examine the micro-structural properties of various compounds. The XRD patterns of different prolamins are presented in Fig. 5 \& S4. A broad hump at around $20^{\circ}$ indicates the amorphous nature in all the samples which was also reported by 47 in gliadin. High Glu and Pro content was observed in prolamins which might have contributed this amorphous structure ${ }^{48}$. Prolamins from different cultivars showed diffraction peaks at $2 \theta$ values of $10.4^{\circ}, 37.8^{\circ}$ and $44.1^{\circ}$ which indicated the existence of a regular periodic arrangement of molecules or crystallinity.

The size of the crystallites corresponding to above mentioned diffraction peaks was determined using Scherrer's formula (Eq. 4). The crystallite size corresponding to $44.1^{\circ}$ diffraction peaks in gliadin, secalin and hordein varied from $12.29-13.67 \mathrm{~nm}, 12.47-13.05 \mathrm{~nm}$ and $12.29-14.13 \mathrm{~nm}$ respectively (Table 3$)$. The relatively smaller crystallite size at $37.8^{\circ}$ diffraction peaks was observed in gliadin (11.23 - $\left.14.33 \mathrm{~nm}\right)$ followed by hordein $(13.40-16.63 \mathrm{~nm})$ and secalin $(14.01-17.31 \mathrm{~nm})$. Variable sizes were observed at $10.4^{\circ}$ diffraction peak in gliadin (13.05 - $\left.17.94 \mathrm{~nm}\right)$, hordein (16.79 $17.94 \mathrm{~nm}$ ) and secalin (15.47 - $18.35 \mathrm{~nm}$ ). The regular arrangement can be classified into Category I-comprises of three organized patterns corresponding to $10.4^{\circ}, 37.8^{\circ}$ and $44.1^{\circ}$ diffraction peaks and Category $\mathrm{II}$ - comprises of two organised patterns corresponding to $10.4^{\circ}$ and $44.1^{\circ}$. The pattern of category I exists in most of the prolamins, whereas category II is found in small number of prolamin i.e., gliadins (HPW-42, HPW-155, HPW-249) and hordein (BH-946). Jia et al. ${ }^{47}$ also reported crystalline peaks in XRD analysis of gliadin, however these peaks were at different position.

The inter-planar spacing, 'd', was calculated from the peak positions using Bragg's equation (Table 4). The inter-planar spacing corresponding to the diffraction peak at $44.1^{\circ}$ was $2.05 \AA$, $37.8^{\circ}$ was $2.37-2.38 \AA$ and $10.4^{\circ}$ was $8.46-8.51 \AA$. The ' $d^{\prime}$ 'values for $44.1^{\circ}$ and $37.8^{\circ}$ did not vary much among the prolamins, but for $10.4^{\circ}$ it varied from $8.46-8.48 \AA$ in gliadin, $8.48-8.51 \AA$ in secalin and hordein. Markgren et al., ${ }^{9}$ reported that a-gliadin and LMW-GS showed a similar secondary structure propensity in the absence of intra-molecular disulphide bonds with a relatively uniform distribution of a-helix and/or $\beta$-sheet whereas when intra-molecular disulfide bonds are involved there is an increased tendency for $\beta$-sheet/strand for the amino acid involved in these specific bonds. It can be inferred from the previous study that the prolamins under investigation also had a-helix and/or $\beta$-strand structures.

Transmission Electron Microscopy. Transmission Electron Microscopy was used to study the morphology and microstructure of prolamins. The micrograph was analysis for morphology (Fig. 6), lattice planes (Fig.7) and ring diffraction patterns of selected area (Fig. 8). Morphology of gliadin, secalin and hordein showed a compact spherical structure (Fig 6) which might be due to active participation of $a / \beta$-gliadins polypeptides ${ }^{36}$. A rod like structure was also observed in gliadin due to folding of a sheet with an average diameter of $17.94 \mathrm{~nm}$ and length of $250 \mathrm{~nm}$. Formation of such structures is attributed to involvement of $\omega$ and $\gamma$-gliadin polypeptides ${ }^{36}$. Ang et al., ${ }^{49}$ also supported the existence of two structures of gliadin as compact globular and rod-shaped. The histogram representing the particle size distribution of compact globular structures in prolamin and rod structure of gliadin (Fig. S5). The average particle size was found to be smallest for gliadin (3.88nm), followed by hordein (4.32 $\mathrm{nm})$ and largest in secalin (5.79nm).

The inter-planar spacing calculated from HR-TEM images are presented in Fig. (7 and 8), shows the SAED patterns of the gliadin, secalin and hordein. Two kinds of patterns were observed for different samples, one consisting of sharp, concentric rings and each ring corresponds to specific lattice plane, second diffused rings which indicate lesser orderly arrangement of molecules i.e. poor crystallinity. The patterns show the gliadin and secalin possess higher 
crystallinity as compared to hordein and this observation is consistent with that made from XRD patterns of the samples. The reciprocal of the radius of each ring in the SAED ring pattern is a measure of inter-planar spacing corresponding to specific lattice planes. The calculated ' $\mathrm{d}$ ' spacing is in the range of $2.05-2.97 A^{\circ}$ with gliadin having the least value $\left(2.05 A^{\circ}\right)$ and secalin having the highest $\left(2.97 A^{\circ}\right)$. The values of inter-planar spacing from HR-TEM SAED lattice pattern were found to be in the range of $3.23-3.48 A^{\circ}$, where hordein having the highest value $\left(3.48 A^{\circ}\right)$, followed by secalin $\left(3.37 A^{\circ}\right)$ and the least in gliadin $\left(3.23 \mathrm{~A}^{\circ}\right)$.

Comparison between advance analytical techniques. Particle size of the prolamins observed for gliadin (1.12 - $6.06 \mathrm{~nm})$, secalin (3.23 - 9.47 $\mathrm{nm})$ and hordein $(2.13-6.83 \mathrm{~nm})$ using TEM whereas for gliadin $(1.23-1.83 \mathrm{~nm})$, secalin $(6.45-11.96 \mathrm{~nm})$ and hordein $(6.67-7.62 \mathrm{~nm})$ using DLS. Particle size of gliadin was on the higher side in TEM but in case of secalin and hordein, it was on the higher side in DLS. However, the particle size range overlapped in all the three prolamins.

The crystalline microstructure of prolamin was shown by both XRD and TEM studies. The d-spacing was estimated from HR-TEM lattice plane pattern, Selected Area Electron Diffraction (SAED) ring diffraction pattern and XRD data. The d-spacing observed by HR-TEM, SAED and XRD for gliadin was 2.04 $A^{\circ}, 3.23 A^{\circ}$ and $2.05-8.48 A^{\circ}$ whereas for hordein it was 2.06, 3.48 and 2.05-8.51 $A^{\circ}$ while for secalin it was 2.97, 3.37 and 2.05- 8.51 $A^{\circ}$ respectively. HRTEM and SAED gave one value of $d$-spacing whereas XRD has given three values of $d$-spacing. It indicates that there are three types of crystalline structure in the prolamins as per XRD and one crystalline structure as per TEM analysis. Further the crystalline pattern showed that gliadin and secalin possessed relatively high ordered crystallinity than hordein.

These periodic regular arrangements probably attributed to the subsistence of $\beta$-sheet structure among the prolamin and disulphide bonding as a result of intra-molecular interaction which mainly involves cysteine residues in polypeptide chains ${ }^{50}$. Markgren et al., ${ }^{9}$ highlighted the role of cysteine amino acid in intra-molecular disulphide bonding, which when located in more hydrophobic motif and stated that the intra-molecular interaction enhances the tendency of formation of more ordered $\beta$-sheet configuration. Similarly, ${ }^{51}$ also reported the crystalline structure of proteins by XRD studies and attributed it to the $\beta$ sheet structure. Rasheed et al., ${ }^{52}$ have also reported that the modified gliadin with nano-crystalline structure consists of high proportion of $\beta$-sheet structure along with irreversible linkages such as covalent disulphide bonds.

\section{Conclusion}

The gliadin, secalin and hordein were extracted following ${ }^{11}$ method and examined using advance techniques. Gliadin has more protein content than secalin and hordein. The amino acid composition reveals that prolamin is abundant in glutamic acid and proline content among the non-essential amino acids while isoleucine and phenylalanine among the essential amino acids. Glutamic acid and proline sequence triggers the autoimmune response resulting in celiac disease. Tryptophan remained intact in the protocol due to mild degradation conditions and presence of mercaptoethanol. The extraction method was able to exclude LMW-GS in all the prolamin which was the major problem in other extraction protocols. SEM images shows globular morphology of gliadin while sheet like or stacked flaky morphology of hordein and secalin. Prolamin sizes determined by TEM and DLS were in close proximity. Results indicated that prolamin had both amorphous as well as crystalline structure.

\section{Declarations}

\section{Conflict of interests}

None

\section{Acknowledgements:}

Authors are highly thankful to the UGC, Delhi, for providing BSR fellowship to Monika Rani (letter no.25-1/2014-15(BSR)/7-398/2012/(BSR)). We are also highly thankful to Dr H. K Chaudhary, Professor and Head of Genetics and Plant Breeding and Agricultural Biotechnology at CSK Himachal Pradesh Agriculture University, Palampur, for providing us research rye and wheat samples.

\section{Credit Author Statement}

Monika Rani: Methodology, Formal Analysis, Data curation, Investigation, Writing- Original draft preparation, Reviewing and editing.

Dalbir Singh Sogi: Conceptualization, Supervision, Resources, Reviewing and editing, Funding acquisition.

Balmeet Singh Gill: Supervision.

\section{References}

1. Kasarda, D. D., Bernardin, J. E. \& Nimmo, C. C. Advances in cereal science and technology AACC. 1, (1976).

2. Balakireva, A. V. \& Zamyatnin, A. A. Properties of gluten intolerance: Gluten structure, evolution, pathogenicity and detoxification capabilities. Nutrients. 8, 1-27 (2016).

3. Scherf, K. A. et al. Recent Progress and Recommendations on Celiac Disease From the Working Group on Prolamin Analysis and Toxicity. Frontiers in Nutrition. 7, 1-14 (2020). 
4. Ratsch, I. M. \& Catassi, C. Coeliac disease: a potentially treatable health problem of Saharawi refugee children. Bulletin of the World Health Organization. 541-545 https://doi.org/10.1590/S0042-96862001000600010 (2001).

5. Feng, J. et al. Physicochemical and Engineering Aspects Gliadin nanoparticles stabilized by a combination of thermally denatured ovalbumin with gemini dodecyl 0 -glucoside: The modulating effect of cosurfactant. Colloids and Surfaces A: Physicochemical and Engineering Aspects. 516, 94105 (2017).

6. Reddy, N. \& Yang, Y. Potential of plant proteins for medical applications. Trends in Biotechnology. 29, 490-498 (2011).

7. Luo, Y. \& Hu, Q. 7 - Food-derived biopolymers for nutrient delivery. in Nutrient Delivery: Nanotechnology in the Agri-Food Industry (ed. Alexandru Mihai Grumezescu) 251-291(Academic Press, Elsevier Inc., 2017). doi:10.1016/B978-0-12-804304-2/00007-X

8. Elzoghby, A. O., Samy, W. M. \& Elgindy, N. A. Protein-based nanocarriers as promising drug and gene delivery systems. Journal of Controlled Release. 161, 38-49 (2012).

9. Markgren, J., Hedenqvist, M., Rasheed, F., Skepö, M. \& Johansson, E. Glutenin and Gliadin, a Piece in the Puzzle of their Structural Properties in the Cell Described through Monte Carlo Simulations. Biomolecules 10, Article 1095(2020).

10. Fu, B. X. \& Kovacs, M. I. P. Rapid Single-Step Procedure for Isolating Total Glutenin Proteins of Wheat Flour *. Journal of Cereal Science. 29, $113-116$ (1999).

11. DuPont, F. M., Chan, R., Lopez, R. \& Vensel, W. H. Sequential extraction and quantitative recovery of gliadins, glutenins, and other proteins from small samples of wheat flour. Journal of Agricultural and Food Chemistry. 53, 1575-1584 (2005).

12. Field, J. M., Shewry, P. R. \& Miflin, B. J. The Purification and Characterization of Homologous High Molecular Weight Storage Proteins from Grain of Wheat, Rye and Barley. Theoretical and Applied Genetics. 62, 329-336 (1982).

13. Ribeiro, M., Seabra, L., Ramos, A. \& Santos, S. Polymorphism of the storage proteins in Portuguese rye (Secale cereale L.) populations. Hereditas. 149, 72-84 (2012).

14. AACC \& Cereals Approved Methods of Analysis. \& Grains Association. (2010).

15. Siddiqi, R. A., Singh, T. P., Rani, M., Sogi, D. S. \& Bhat, M. A. Diversity in Grain, Flour, Amino Acid Composition, Protein Profiling, and Proportion of Total Flour Proteins of Different Wheat Cultivars of North India. Frontiers in Nutrition. 7, 141 (2020).

16. Schalk, K., Lexhaller, B., Koehler, P. \& Scherf, K. A. Isolation and characterization of gluten protein types from wheat, rye, barley and oats for use as reference materials. PLOS ONE. 12, 1-20 (2017).

17. Monshi, A., Foroughi, M. R. \& Monshi, M. R. Modified Scherrer Equation to Estimate More Accurately Nano-Crystallite Size Using XRD. World Journal of Nano Science and Engineering. 2, 154-160 (2012).

18. Hou, Q., Bourgeas, R., Pucci, F. \& Rooman, M. Computational analysis of the amino acid interactions that promote or decrease protein solubility. Sci. Rep. 8, 1-13 (2018).

19. Cummings, A. E. et al. $\beta$-Branched Amino Acids Stabilize Specific Conformations of Cyclic Hexapeptides. Biophys. J. 116, 433-444 (2019).

20. Wang, Y. \& Chen, L. Electrospinning of Prolamin Proteins in Acetic Acid: The Effects of Protein Conformation and Aggregation in Solution. Molecular Material and Engineering. 297, 902-913 (2012).

21. Rutherfurd, S. M. \& Gilani, G. S. Amino Acid Analysis Shane. Current Protocols in Protein Science 58, 11.9.1-11.9.37(2009).

22. Li, S. C., Goto, N. K., Williams, K. A. \& Deber, C. M. a-Helical, but not $\beta$-sheet, propensity of proline is determined by peptide environment. Proceedings of the National Academy of Sciences of the United States of America. 93, 6676-6681 (1996).

23. Amundarain, J. et al. Molecular mechanisms of 33-mer gliadin peptide oligomerisation. Physical Chemistry Chemical Physics. 21, 22539-22552 (2019).

24. Šterna, V., Zute, S. \& Jakobsone, I. Grain composition and functional ingredients of barley varieties created in Latvia. Proceedings of the Latvian Academy of Sciences, Section B: Natural, Exact, and Applied Sciences 69, 158-162(2015).

25. Gellrich, C., Schieberle, P. \& Wieser, H. Biochemical Characterization and Quantification of the Storage Protein (Secalin) Types in Rye Flour. Cereal Chem. 80, 102-109 (2003).

26. FAO. Dietary protein quality evaluation in human nutrition: Report of an FAO expert consultation. Food and nutrition paper; 92 FAO: Rome (2013).

27. Oliete, B. et al. Use of wheat, triticale and rye flours in layer cake production. International Journal of Food Science and Technology. 45, 697-706 (2010).

28. Drakos, A. et al. Influence of jet milling and particle size on the composition, physicochemical and mechanical properties of barley and rye flours. Food Chem. 215, 326-332 (2017).

29. Pommié, C., Levadoux, S., Sabatier, R., Lefranc, G. \& Lefranc, M. P. IMGT standardized criteria for statistical analysis of immunoglobulin V-Region amino acid properties. Journal of Molecular Recognition. 17, 17-32 (2004).

30. Lexhaller, B., Colgrave, M. L. \& Scherf, K. A. Characterization and Relative Quantitation of Wheat, Rye, and Barley Gluten Protein Types by Liquid Chromatography - Tandem Mass Spectrometry. Frontiers in Plant Science. 10, 1530 (2019).

31. Anjum, F. M. et al. Wheat gluten: High molecular weight glutenin subunits - Structure, genetics, and relation to dough elasticity. Journal of Food Science. 72, 56-63 (2007).

32. Petrovičová, L., Gálová, Z. \& Chňapek, M. Genetic diversity of czechoslovak origin rye varieties (secale cereale L.) based on protein polymorphism. Journal of Microbiology, Biotechnology and Food Sciences. 3, 267-269 (2014).

Page $11 / 17$ 
33. Gálová, Z. et al. Protein profiles of cereals and pseudocereals determined by two-dimensional gel electrophoresis. Journal of Microbiology, Biotechnology and Food Sciences. 9, 359-365 (2019).

34. Wieser, H. \& Kieffer, R. Correlations of the amount of gluten protein types to the technological properties of wheat flours determined on a micro-scale. Journal of Cereal Science. 34, 19-27 (2001).

35. Dhaka, V. \& Khatkar, B. S. Effects of gliadin/glutenin and HMW-GS/LMW-GS ratio on dough rheological properties and bread-making potential of wheat varieties. Journal of Food Quality. 38, 71-82 (2015).

36. Taylor, P., Barak, S., Mudgil, D. \& Khatkar, B. S. Biochemical and Functional Properties of Wheat Gliadins: A Review Biochemical and Functional Properties of Wheat Gliadins. Critical Reviews in Food Science and Nutrition. 55, 357-368 (2015).

37. Paananen, A. et al. Nanomechanical Force Measurements of Gliadin Protein Interactions. Biopolymers. 83, 658-667 (2006).

38. Zhang, Y. et al. Deletion of high-molecular-weight glutenin subunits in wheat significantly reduced dough strength and bread-baking quality. $B M C$ Plant Biology. 18, 319 (2018).

39. Wieser, H. Chemistry of gluten proteins. Food Microbiol. 24, 115-119 (2007).

40. Socha, P. et al. Comparable efficiency of different extraction protocols for wheat and rye prolamins. (2016). doi:10.5219/540

41. Mickowska, B., Socha, P. \& Urminská, D. Immunochemical evaluation of proteolysis of cereal proteins causing celiac disease by microbial proteases. 0105, (2016).

42. Prasanna, P. M. \& Chandiran, I. S. F. ormulation and evaluation of loperamide loaded polysorbate 80 and peg conjoined coated nano liposomes. International Journal of Life Science and Pharma Research. 6, 26-33 (2016).

43. Zavareze, R. et al. Production and characterization of encapsulated antioxidative protein hydrolysates from Whitemouth croaker (Micropogonias furnieri) muscle and byproduct. LWT - Food Science and Technology. 59, 841-848 (2014).

44. Wouters, A. G. B., Joye, I. J. \& Delcour, J. A. Understanding the air-water interfacial behavior of suspensions of wheat gliadin nanoparticles.Food Hydrocolloids102, Article 105638 (2020).

45. Peng, D. et al. Foaming and surface properties of gliadin nanoparticles: Influence of pH and heating temperature. Food Hydrocoll. 77, 107-116 (2017).

46. Herrera, M. G., Veuthey, T. V. \& Dodero, V. I. Colloids and Surfaces B: Biointerfaces Self-organization of gliadin in aqueous media under physiological digestive pHs. Colloids and Surfaces B: Biointerfaces. 141, 565-575 (2016).

47. Jia, F. et al. Grain \& Oil Science and Technology Physicochemical and structural characteristics of the Venn components of wheat gliadin. Grain \& Oil Science and Technology. 3, 18-24 (2020).

48. Theillet, F. X. et al. The alphabet of intrinsic disorder. Intrinsically Disordered Proteins. 1, e24360 (2013).

49. Ang, S. et al. Structure and heterogeneity of gliadin: a hydrodynamic evaluation. Eur. Biophys. J. 39, 255-261 (2010).

50. Bhattacharyya, R. \& Pal, D. Disulfide bonds, their stereospecific environment and conservation in protein structures. Protein Eng. Des. Sel. 17, 795-808 (2004).

51. Jung, H. et al. Molecular tandem repeat strategy for elucidating mechanical properties of high-strength proteins. Proceedings of the National Academy of Sciences of the United States of America. 113, 6478-6483 (2016).

52. Rasheed, F., Newson, W. R. \& Kuktaite, R. Structural architecture and solubility of native and modified gliadin and glutenin proteins: Non-crystalline molecular and atomic organization. Royal Society of Chemistry. 4, 2051-2060 (2014).

\section{Tables}

Table 1. IMGT (ImMunoGeneTics) Amino Acid Classification (Pommie et al.,2004) of different cultivars of gliadin, secalin and hordein ( $\mathrm{g}$ amino acid/100 g protein). Mean $\pm \mathrm{SD}$ with different superscripts in column differ significantly $(p \leq 0.05) ; n=3$ for each treatment.

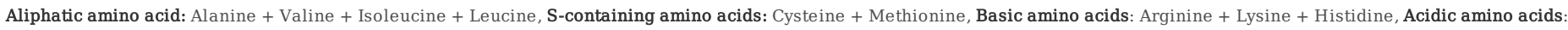

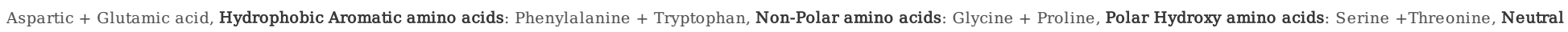
Aromatic amino acids: Tyrosine.

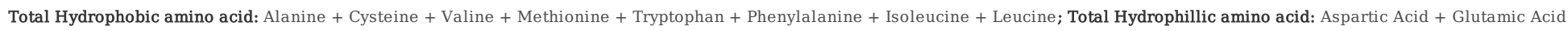
+ Arginine + Lysine; Neutral amino acid: Serine + Histidine + Glycine + Threonine + Tyrosine + Proline. 


\begin{tabular}{|c|c|c|c|c|c|c|c|c|c|c|c|}
\hline \multirow[t]{2}{*}{ Prolamin } & \multicolumn{4}{|c|}{ Hydrophobic Group } & \multicolumn{3}{|c|}{ Hydrophillic Group } & \multicolumn{4}{|c|}{ Neutral Group } \\
\hline & Aliphatic AA & $\begin{array}{c}\text { S-containing } \\
\text { AA }\end{array}$ & $\begin{array}{l}\text { Hydrophobic } \\
\text { Aromatic AA }\end{array}$ & $\begin{array}{c}\text { Total } \\
\text { Hydrophobic } \\
\text { AA }\end{array}$ & Basic AA & Acidic AA & $\begin{array}{c}\text { Total } \\
\text { Hydrophillic } \\
\text { AA }\end{array}$ & $\begin{array}{c}\text { Non-Polar } \\
\text { AA }\end{array}$ & $\begin{array}{c}\text { Polar (Hydroxyl } \\
\text { AA) }\end{array}$ & $\begin{array}{c}\text { Neutral } \\
\text { Aromatic AA }\end{array}$ & $\begin{array}{c}\text { Total } \\
\text { Neutral AA }\end{array}$ \\
\hline \multicolumn{12}{|l|}{ Gliadin } \\
\hline HPW-42 & $17.23 \pm 0.21^{\mathrm{A}}$ & $1.58 \pm 0.01^{\mathrm{C}}$ & $8.36 \pm 0.57^{\mathrm{A}}$ & $27.17 \pm 0.37^{\mathrm{A}}$ & $8.23 \pm 1.01^{\mathrm{DEF}}$ & $40.04 \pm 3.08^{\mathrm{AB}}$ & $48.27 \pm 2.07^{\mathrm{A}}$ & $14.21 \pm 1.58^{\mathrm{A}}$ & $7.47 \pm 0.27^{\mathrm{BCDEF}}$ & $2.88 \pm 0.39^{\mathrm{BC}}$ & $24.57 \pm 1.70^{\mathrm{A}}$ \\
\hline $\begin{array}{c}\text { HPW- } \\
147\end{array}$ & $18.17 \pm 1.24^{\mathrm{A}}$ & $2.03 \pm 0.30^{\mathrm{ABC}}$ & $9.45 \pm 0.72^{\mathrm{A}}$ & $29.66 \pm 1.66^{\mathrm{A}}$ & $6.82 \pm 1.22^{\mathrm{F}}$ & $40.32 \pm 0.66^{\mathrm{AB}}$ & $47.14 \pm 1.88^{\mathrm{A}}$ & $14.00 \pm 2.06^{\mathrm{A}}$ & $6.46 \pm 0.92^{\mathrm{F}}$ & $2.73 \pm 0.93^{\mathrm{BC}}$ & $23.20 \pm 0.21^{\mathrm{A}}$ \\
\hline $\begin{array}{c}\text { HPW- } \\
155\end{array}$ & $18.90 \pm 1.99^{\mathrm{A}}$ & $1.52 \pm 0.09^{C}$ & $8.21 \pm 0.16^{\mathrm{A}}$ & $28.63 \pm 2.25^{\mathrm{A}}$ & $6.16 \pm 0.42^{\mathrm{F}}$ & $39.15 \pm 4.14^{\mathrm{ABC}}$ & $45.31 \pm 3.72^{\mathrm{A}}$ & $15.73 \pm 3.74^{\mathrm{A}}$ & $7.43 \pm 1.17^{\mathrm{CDEF}}$ & $2.90 \pm 1.05^{\mathrm{ABC}}$ & $26.06 \pm 5.96^{\mathrm{A}}$ \\
\hline $\begin{array}{c}\text { HPW- } \\
236\end{array}$ & $16.76 \pm 0.17^{\mathrm{A}}$ & $1.73 \pm 0.27^{\mathrm{BC}}$ & $8.59 \pm 0.91^{\mathrm{A}}$ & $27.08 \pm 1.36^{\mathrm{A}}$ & $8.42 \pm 0.13^{\mathrm{DEF}}$ & $41.15 \pm 0.94^{\mathrm{A}}$ & $49.57 \pm 0.82^{\mathrm{A}}$ & $13.67 \pm 1.29^{\mathrm{A}}$ & $6.63 \pm 0.42^{\mathrm{EF}}$ & $3.04 \pm 0.32^{\mathrm{ABC}}$ & $23.34 \pm 0.55^{\mathrm{A}}$ \\
\hline $\begin{array}{c}\text { HPW- } \\
249\end{array}$ & $16.98 \pm 0.34^{\mathrm{A}}$ & $2.03 \pm 1.12^{\mathrm{ABC}}$ & $7.87 \pm 1.28^{\mathrm{A}}$ & $26.89 \pm 0.18^{\mathrm{A}}$ & $6.37 \pm 0.58^{\mathrm{F}}$ & $43.65 \pm 1.38^{\mathrm{A}}$ & $50.02 \pm 1.96^{\mathrm{A}}$ & $13.49 \pm 2.79^{\mathrm{A}}$ & $6.89 \pm 0.11^{\mathrm{DE}} \mathrm{F}$ & $2.71 \pm 0.90^{\mathrm{BC}}$ & $23.09 \pm 1.78^{\mathrm{A}}$ \\
\hline $\begin{array}{c}\text { HPW- } \\
349\end{array}$ & $16.86 \pm 2.17^{\mathrm{A}}$ & $2.18 \pm 0.09^{\mathrm{ABC}}$ & $9.30 \pm 0.51^{\mathrm{A}}$ & $28.34 \pm 2.59^{\mathrm{A}}$ & $7.34 \pm 0.55^{\mathrm{EF}}$ & $41.03 \pm 2.10^{\mathrm{A}}$ & $48.38 \pm 1.56^{\mathrm{A}}$ & $12.08 \pm 1.43^{\mathrm{A}}$ & $7.64 \pm 0.50^{\mathrm{BCDEF}}$ & $3.56 \pm 0.10^{\mathrm{ABC}}$ & $23.28 \pm 1.03^{\mathrm{A}}$ \\
\hline \multicolumn{12}{|l|}{ Secalin } \\
\hline $\begin{array}{c}\text { MCTLG- } \\
1\end{array}$ & $16.76 \pm 0.25^{\mathrm{A}}$ & $3.19 \pm 0.19^{\mathrm{AB}}$ & $8.45 \pm 0.89^{\mathrm{A}}$ & $28.40 \pm 1.33^{\mathrm{A}}$ & $11.20 \pm 0.78^{\mathrm{ABCDE}}$ & $36.25 \pm 3.98^{\mathrm{ABC}}$ & $47.45 \pm 3.20^{\mathrm{A}}$ & $11.82 \pm 2.30^{\mathrm{A}}$ & $9.37 \pm 0.20^{\mathrm{ABC}}$ & $2.97 \pm 0.62^{\mathrm{ABC}}$ & $24.15 \pm 1.87^{\mathrm{A}}$ \\
\hline $\begin{array}{c}\text { MCTLG- } \\
2\end{array}$ & $16.59 \pm 0.64^{\mathrm{A}}$ & $3.19 \pm 0.02^{\mathrm{AB}}$ & $8.84 \pm 0.28^{\mathrm{A}}$ & $28.62 \pm 0.93^{\mathrm{A}}$ & $11.62 \pm 0.18^{\mathrm{ABCD}}$ & $36.11 \pm 0.71^{\mathrm{ABC}}$ & $47.72 \pm 0.53^{\mathrm{A}}$ & $12.28 \pm 0.67^{\mathrm{A}}$ & $8.95 \pm 0.24^{\mathrm{ABCDE}}$ & $2.42 \pm 0.03^{\mathrm{BC}}$ & $23.65 \pm 0.40^{\mathrm{A}}$ \\
\hline $\begin{array}{c}\text { MCTLG- } \\
3\end{array}$ & $17.43 \pm 1.00^{\mathrm{A}}$ & $3.39 \pm 0.30^{\mathrm{A}}$ & $10.04 \pm 0.56^{\mathrm{A}}$ & $30.86 \pm 0.15^{\mathrm{A}}$ & $11.44 \pm 0.07^{\mathrm{ABCDE}}$ & $36.47 \pm 3.02^{\mathrm{ABC}}$ & $47.92 \pm 3.09^{\mathrm{A}}$ & $9.99 \pm 1.74^{\mathrm{A}}$ & $9.34 \pm 0.80^{\mathrm{AB}} \mathrm{CD}$ & $1.90 \pm 0.70^{\mathrm{BC}}$ & $21.23 \pm 3.24^{\mathrm{A}}$ \\
\hline $\begin{array}{c}\text { MCTLG- } \\
4\end{array}$ & $16.76 \pm 0.51^{\mathrm{A}}$ & $2.97 \pm 0.40^{\mathrm{ABC}}$ & $10.03 \pm 0.10^{\mathrm{A}}$ & $29.76 \pm 0.21^{\mathrm{A}}$ & $10.04 \pm 0.92^{\mathrm{BCDEF}}$ & $37.30 \pm 1.86^{\mathrm{BC}}$ & $47.35 \pm 0.93^{\mathrm{A}}$ & $11.38 \pm 0.49^{\mathrm{A}}$ & $9.02 \pm 0.54^{\mathrm{ABCDE}}$ & $2.49 \pm 0.11^{\mathrm{BC}}$ & $22.89 \pm 1.14^{\mathrm{A}}$ \\
\hline $\begin{array}{c}\text { MCTLG- } \\
5\end{array}$ & $17.62 \pm 1.82^{\mathrm{A}}$ & $3.02 \pm 0.44^{\mathrm{ABC}}$ & $7.35 \pm 0.41^{\mathrm{A}}$ & $27.99 \pm 1.85^{\mathrm{A}}$ & $8.95 \pm 0.47^{\mathrm{CDEF}}$ & $43.14 \pm 2.56^{\mathrm{A}}$ & $52.10 \pm 2.08^{\mathrm{A}}$ & $8.70 \pm 0.03^{A}$ & $9.88 \pm 0.23^{\mathrm{ABC}}$ & $1.33 \pm 0.44^{\mathrm{C}}$ & $19.91 \pm 0.23^{\mathrm{A}}$ \\
\hline \multicolumn{12}{|l|}{ Hordein } \\
\hline BH-393 & $16.30 \pm 0.65^{\mathrm{A}}$ & $3.04 \pm 0.02^{\mathrm{ABC}}$ & $8.88 \pm 0.64^{\mathrm{A}}$ & $28.22 \pm 1.31^{\mathrm{A}}$ & $11.48 \pm 0.98^{\mathrm{ABCDE}}$ & $31.74 \pm 1.48^{\mathrm{BC}}$ & $43.22 \pm 0.50^{\mathrm{A}}$ & $14.01 \pm 1.79^{\mathrm{A}}$ & $10.44 \pm 0.05^{\mathrm{A}}$ & $4.11 \pm 0.03^{\mathrm{AB}}$ & $28.55 \pm 1.82^{\mathrm{A}}$ \\
\hline BH-902 & $18.52 \pm 0.95^{\mathrm{A}}$ & $2.79 \pm 0.34^{\mathrm{ABC}}$ & $7.94 \pm 0.69^{\mathrm{A}}$ & $29.24 \pm 0.08^{\mathrm{A}}$ & $13.20 \pm 0.04^{\mathrm{AB}}$ & $30.23 \pm 0.76^{\mathrm{C}}$ & $43.43 \pm 0.80^{\mathrm{A}}$ & $13.54 \pm 0.38^{\mathrm{A}}$ & $9.89 \pm 0.83^{\mathrm{ABC}}$ & $3.90 \pm 0.28^{\mathrm{AB}}$ & $27.33 \pm 0.72^{\mathrm{A}}$ \\
\hline BH-946 & $18.07 \pm 0.52^{\mathrm{A}}$ & $3.26 \pm 0.16^{\mathrm{AB}}$ & $8.15 \pm 0.44^{\mathrm{A}}$ & $29.48 \pm 0.81^{\mathrm{A}}$ & $15.08 \pm 2.81^{\mathrm{A}}$ & $31.26 \pm 1.65^{\mathrm{BC}}$ & $46.34 \pm 4.46^{\mathrm{A}}$ & $12.19 \pm 1.70^{\mathrm{A}}$ & $8.60 \pm 1.09^{\mathrm{AB}} \mathrm{CDEF}$ & $3.39 \pm 0.86^{\mathrm{ABC}}$ & $24.18 \pm 3.65^{\mathrm{A}}$ \\
\hline BH-959 & $17.59 \pm 2.24^{\mathrm{A}}$ & $3.30 \pm 0.46^{\mathrm{A}}$ & $8.33 \pm 1.56^{\mathrm{A}}$ & $29.23 \pm 1.13^{\mathrm{A}}$ & $12.95 \pm 1.47^{\mathrm{ABC}}$ & $31.40 \pm 1.75^{\mathrm{BC}}$ & $44.35 \pm 0.28^{\mathrm{A}}$ & $11.32 \pm 0.82^{\mathrm{A}}$ & $9.92 \pm 0.05^{\mathrm{AB}}$ & $5.19 \pm 0.08^{\mathrm{A}}$ & $26.43 \pm 0.85^{\mathrm{A}}$ \\
\hline
\end{tabular}

Table 2. Polydispersity index, hydrodynamic diameter and zeta potential of freeze-dried gliadin, secalin and hordein.

Mean \pm SD with different superscripts in column differ significantly $(p \leq 0.05) ; n=3$ for each treatment

\begin{tabular}{|c|c|c|c|c|c|c|}
\hline \multirow[t]{2}{*}{ Cereal Prolamin } & \multirow[t]{2}{*}{ Polydispersity Index } & \multicolumn{2}{|c|}{ Hydrodynamic diameter $D_{h}(n m)$} & \multicolumn{2}{|c|}{ Number [\%] } & \multirow[t]{2}{*}{ Zeta Potential (mV) } \\
\hline & & Peak 1 & Peak 2 & Peak 1 & Peak 2 & \\
\hline \multicolumn{7}{|l|}{ Gliadin } \\
\hline HPW-42 & $0.51 \pm 0.11^{\mathrm{A}}$ & $1.23 \pm 0.38^{\mathrm{D}}$ & - & $100.00 \pm 0.00^{\mathrm{A}}$ & - & $23.53 \pm 0.46^{\mathrm{B}}$ \\
\hline HPW-147 & $0.59 \pm 0.06^{\mathrm{A}}$ & $1.39 \pm .17^{\mathrm{D}}$ & - & $100.00 \pm 0.00^{\mathrm{A}}$ & - & $27.00 \pm 0.96^{\mathrm{A}}$ \\
\hline HPW-155 & $0.49 \pm 0.04^{\mathrm{A}}$ & $1.71 \pm 0.13^{\mathrm{D}}$ & - & $100.00 \pm 0.00^{\mathrm{A}}$ & - & $25.53 \pm 0.12^{\mathrm{AB}}$ \\
\hline HPW-236 & $0.64 \pm 0.14^{\mathrm{A}}$ & $1.58 \pm 0.09^{\mathrm{D}}$ & - & $100.00 \pm 0.00^{\mathrm{A}}$ & - & $25.93 \pm 0.35^{\mathrm{A}}$ \\
\hline HPW-249 & $0.61 \pm 0.18^{\mathrm{A}}$ & $1.65 \pm 0.10^{\mathrm{D}}$ & - & $100.00 \pm 0.00^{\mathrm{A}}$ & - & $26.10 \pm 0.44^{\mathrm{A}}$ \\
\hline HPW-349 & $0.57 \pm 0.10^{\mathrm{A}}$ & $1.83 \pm 0.13^{\mathrm{D}}$ & - & $100.00 \pm 0.00^{\mathrm{A}}$ & - & $25.10 \pm 1.08^{\mathrm{AB}}$ \\
\hline \multicolumn{7}{|l|}{ Secalin } \\
\hline MCTLG-1 & $0.67 \pm 0.42^{\mathrm{A}}$ & $11.96 \pm 1.58^{\mathrm{B}}$ & $39.82 \pm 3.53^{B}$ & $99.83 \pm 0.06^{\mathrm{A}}$ & $0.17 \pm 0.06^{\mathrm{A}}$ & $14.00 \pm 0.82^{\mathrm{D}}$ \\
\hline MCTLG-2 & $0.87 \pm 0.12^{\mathrm{A}}$ & $10.35 \pm 1.05^{\mathrm{BC}}$ & $39.90 \pm 4.05^{\mathrm{B}}$ & $99.90 \pm 0.00^{\mathrm{A}}$ & $0.10 \pm 0.00^{\mathrm{A}}$ & $16.60 \pm 0.72^{\mathrm{C}}$ \\
\hline MCTLG-3 & $0.74 \pm 0.05^{\mathrm{A}}$ & $18.44 \pm 4.33^{\mathrm{A}}$ & $68.33 \pm 6.58^{\mathrm{A}}$ & $99.90 \pm 0.00^{\mathrm{A}}$ & $0.10 \pm 0.00^{\mathrm{A}}$ & $13.90 \pm 0.53^{\mathrm{D}}$ \\
\hline MCTLG-4 & $0.66 \pm 0.33^{\mathrm{A}}$ & $7.73 \pm 1.79^{\mathrm{BC}}$ & $26.48 \pm 9.83^{\mathrm{C}}$ & $99.63 \pm 0.38^{\mathrm{A}}$ & $0.37 \pm 0.38^{\mathrm{A}}$ & $15.03 \pm 1.42^{C D}$ \\
\hline MCTLG-5 & $0.66 \pm 0.06^{\mathrm{A}}$ & $8.75 \pm 2.08^{\mathrm{BC}}$ & $27.41 \pm 10.62^{\mathrm{BC}}$ & $99.60 \pm 0.52^{\mathrm{A}}$ & $0.40 \pm 0.52^{\mathrm{A}}$ & $11.23 \pm 1.46^{\mathrm{E}}$ \\
\hline \multicolumn{7}{|l|}{ Hordein } \\
\hline BH-393 & $0.83 \pm 0.08^{\mathrm{A}}$ & $6.94 \pm 0.67^{C}$ & - & $100.00 \pm 0.00^{\mathrm{A}}$ & - & $7.98 \pm 0.59^{\mathrm{F}}$ \\
\hline BH-902 & $0.61 \pm 0.10^{\mathrm{A}}$ & $6.67 \pm 1.66^{\mathrm{C}}$ & - & $100.00 \pm 0.00^{\mathrm{A}}$ & - & $4.68 \pm 0.66^{\mathrm{G}}$ \\
\hline BH-946 & $0.58 \pm 0.20^{\mathrm{A}}$ & $7.62 \pm 0.58^{\mathrm{BC}}$ & - & $100.00 \pm 0.00^{\mathrm{A}}$ & - & $4.64 \pm 0.27^{\mathrm{G}}$ \\
\hline BH-959 & $0.71 \pm 0.07^{\mathrm{A}}$ & $7.03 \pm 1.09^{C}$ & - & $100.00 \pm 0.00^{\mathrm{A}}$ & - & $4.10 \pm 0.29^{\mathrm{G}}$ \\
\hline
\end{tabular}

Table 3. Crystallite size of protein against Bragg's angle(2 $\theta)$ showing crystalline structure of gliadin, secalin and hordein by X-ray diffraction technique. 


\begin{tabular}{|c|c|c|c|c|c|c|c|c|}
\hline Gliadin & Peak Position (2 $\theta)$ & Crystallite size (nm) & Secalin & Peak Position (2 $\theta$ ) & Crystallite size (nm) & Hordein & Peak Position (2 $\theta)$ & Crystallite size ( $\mathrm{nm}$ ) \\
\hline \multirow[t]{2}{*}{ HPW-42 } & 44.06 & 12.66 & \multirow[t]{2}{*}{ MCTLG-1 } & 44.08 & 12.66 & \multirow[t]{2}{*}{ BH-393 } & 44.04 & 12.29 \\
\hline & 10.43 & 17.94 & & 10.41 & 16.79 & & 10.41 & 17.16 \\
\hline \multirow[t]{2}{*}{ HPW-147 } & 44.06 & 13.54 & \multirow[t]{2}{*}{ MCTLG-2 } & 44.06 & 12.47 & \multirow[t]{2}{*}{ BH-902 } & 44.07 & 13.05 \\
\hline & 37.83 & 11.23 & & 37.86 & 15.68 & & 37.82 & 16.63 \\
\hline \multirow[t]{3}{*}{ HPW-155 } & 44.04 & 12.29 & \multirow[t]{3}{*}{ MCTLG-3 } & 44.08 & 12.66 & \multirow[t]{3}{*}{ BH-946 } & 44.09 & 14.13 \\
\hline & - & - & & 37.83 & 14.33 & & - & - \\
\hline & 10.43 & 16.11 & & 10.38 & 17.54 & & 10.39 & 16.79 \\
\hline \multirow[t]{3}{*}{ HPW-236 } & 44.11 & 13.67 & \multirow[t]{3}{*}{ MCTLG-4 } & 44.07 & 13.05 & \multirow[t]{3}{*}{ BH-959 } & 44.05 & 12.47 \\
\hline & 37.87 & 14.33 & & 37.92 & 14.01 & & 37.78 & 13.4 \\
\hline & 10.42 & 17.94 & & 10.41 & 16.79 & & 10.4 & 17.54 \\
\hline \multirow[t]{2}{*}{ HPW-249 } & 44.11 & 12.47 & \multirow[t]{2}{*}{ MCTLG-5 } & 44.09 & 12.85 & & & \\
\hline & 10.4 & 17.61 & & 10.41 & 18.35 & & & \\
\hline \multirow[t]{3}{*}{ HPW-349 } & 44.11 & 12.29 & & & & & & \\
\hline & 37.82 & 13.62 & & & & & & \\
\hline & 10.41 & 15.78 & & & & & & \\
\hline
\end{tabular}

Table 4. Comparative d-spacing of protein against Bragg's angle(2 $\theta$ ) showing crystalline structure of gliadin, secalin and hordein by X-ray diffraction technique.

\begin{tabular}{|c|c|c|c|c|c|c|c|c|}
\hline Gliadin & Peak Position (2 $\theta)$ & d-Spacing $\left(A^{0}\right)$ & Secalin & Peak Position (2 $\theta$ ) & d-Spacing $\left(A^{0}\right)$ & Hordein & Peak Position (20) & d-Spacing $\left(A^{0}\right)$ \\
\hline \multirow[t]{3}{*}{ HPW-42 } & 44.06 & 2.05 & \multirow[t]{3}{*}{ MCTLG-1 } & 44.08 & 2.05 & \multirow[t]{3}{*}{ BH-393 } & 44.04 & 2.05 \\
\hline & - & - & & 37.83 & 2.37 & & 37.81 & 2.38 \\
\hline & 10.43 & 8.46 & & 10.41 & 8.48 & & 10.41 & 8.48 \\
\hline \multirow[t]{3}{*}{ HPW-147 } & 44.06 & 2.05 & \multirow[t]{3}{*}{ MCTLG-2 } & 44.06 & 2.05 & \multirow[t]{3}{*}{ BH-902 } & 44.07 & 2.05 \\
\hline & 37.83 & 2.37 & & 37.86 & 2.37 & & 37.82 & 2.38 \\
\hline & 10.41 & 8.48 & & 10.41 & 8.48 & & 10.38 & 8.51 \\
\hline \multirow[t]{3}{*}{ HPW-155 } & 44.04 & 2.05 & \multirow[t]{3}{*}{ MCTLG-3 } & 44.08 & 2.05 & \multirow[t]{3}{*}{ BH-946 } & 44.09 & 2.05 \\
\hline & - & - & & 37.83 & 2.37 & & - & - \\
\hline & 10.43 & 8.46 & & 10.38 & 8.51 & & 10.39 & 8.51 \\
\hline \multirow[t]{3}{*}{ HPW-236 } & 44.11 & 2.05 & \multirow[t]{3}{*}{ MCTLG-4 } & 44.07 & 2.05 & \multirow[t]{3}{*}{ ВН-959 } & 44.05 & 2.05 \\
\hline & 37.87 & 2.37 & & 37.92 & 2.37 & & 37.78 & 2.38 \\
\hline & 10.42 & 8.48 & & 10.41 & 8.48 & & 10.4 & 8.51 \\
\hline \multirow[t]{3}{*}{ HPW-249 } & 44.11 & 2.05 & \multirow[t]{3}{*}{ MCTLG-5 } & 44.09 & 2.05 & & & \\
\hline & - & - & & 37.77 & 2.38 & & & \\
\hline & 10.4 & 8.51 & & 10.41 & 8.48 & & & \\
\hline \multirow[t]{3}{*}{ HPW-349 } & 44.11 & 2.05 & & & & & & \\
\hline & 37.82 & 2.38 & & & & & & \\
\hline & 10.41 & 8.48 & & & & & & \\
\hline
\end{tabular}

\section{Figures}




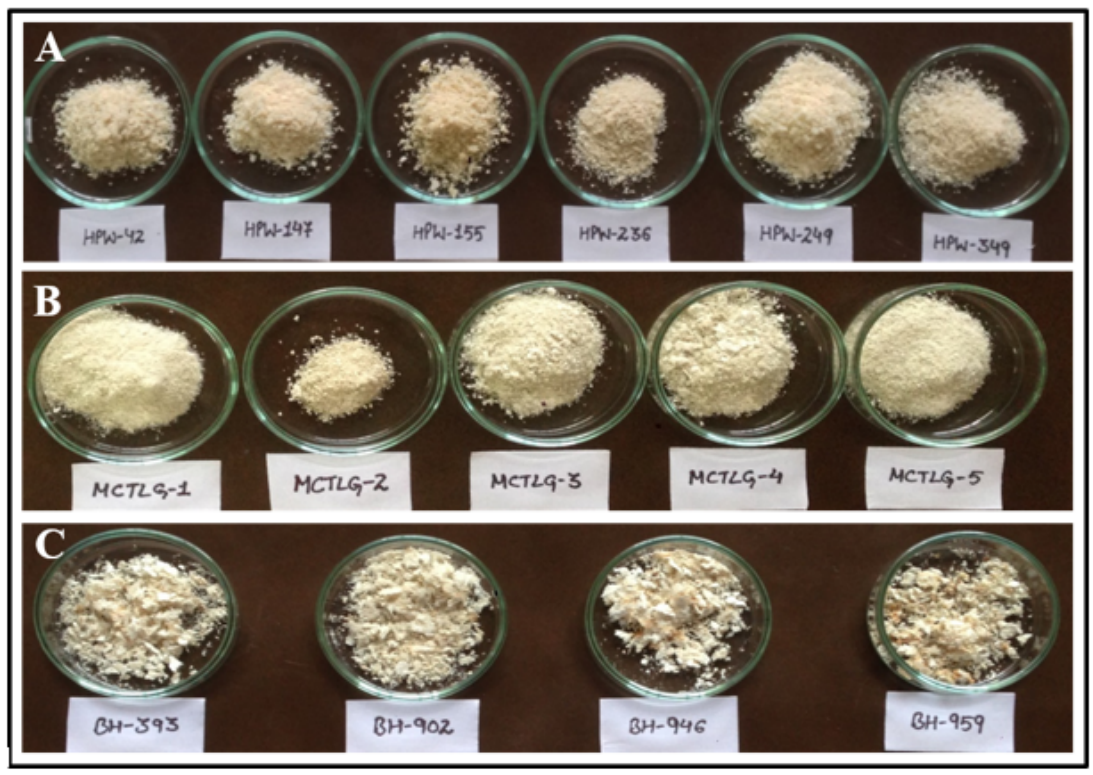

Figure 1

Images of Prolamin (A) gliadin, (B) secalin and (C) hordein extracted with DuPont et al., (2005) eextraction protocol.
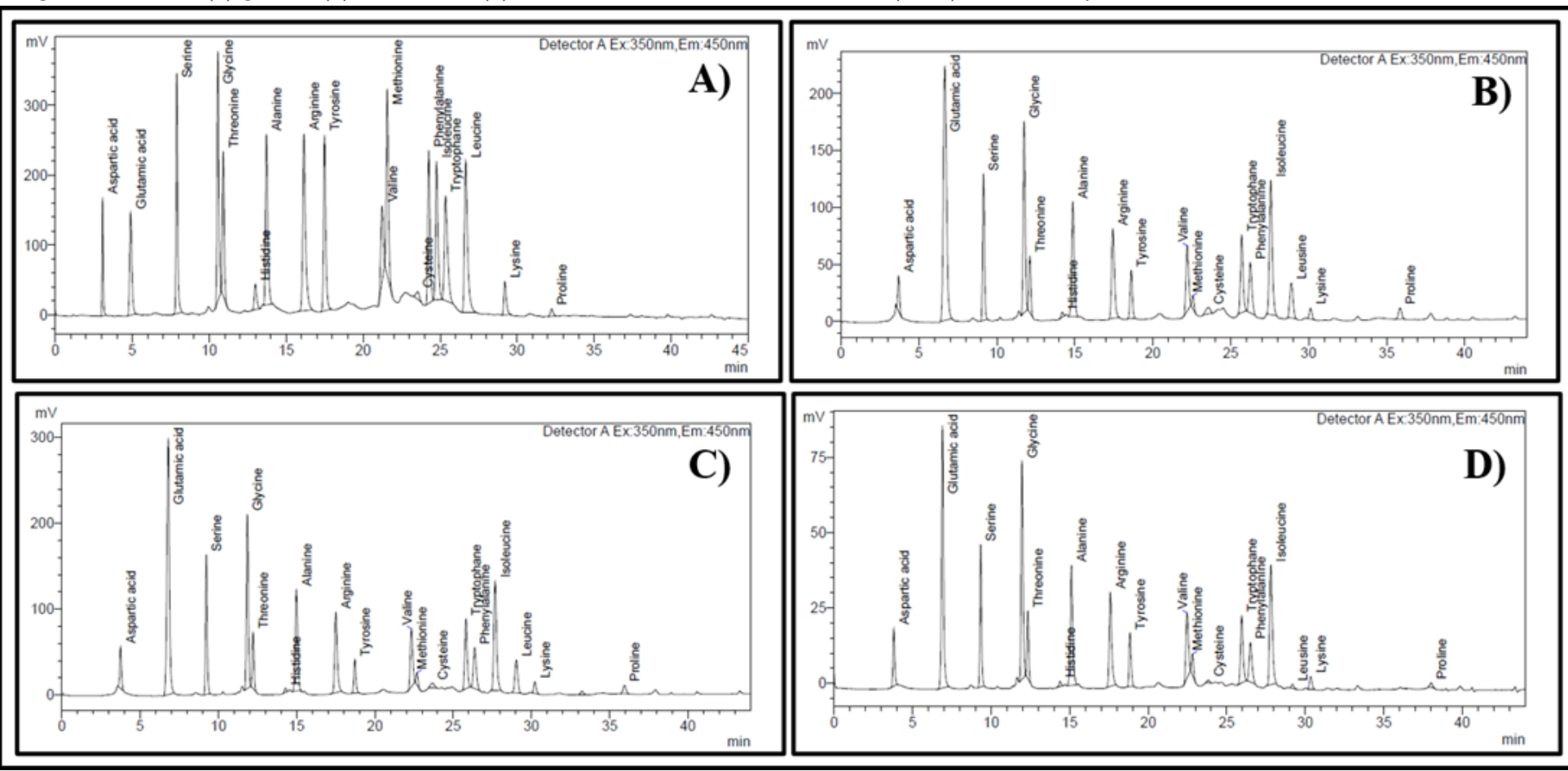

Figure 2

HPLC Chromatograms displaying (A) 500mmol standard mixture of 18 Amino acids; (B) Gliadin, HPW-42 (C) Secalin, MCTLG-1, (D) Hordein, BH-393.

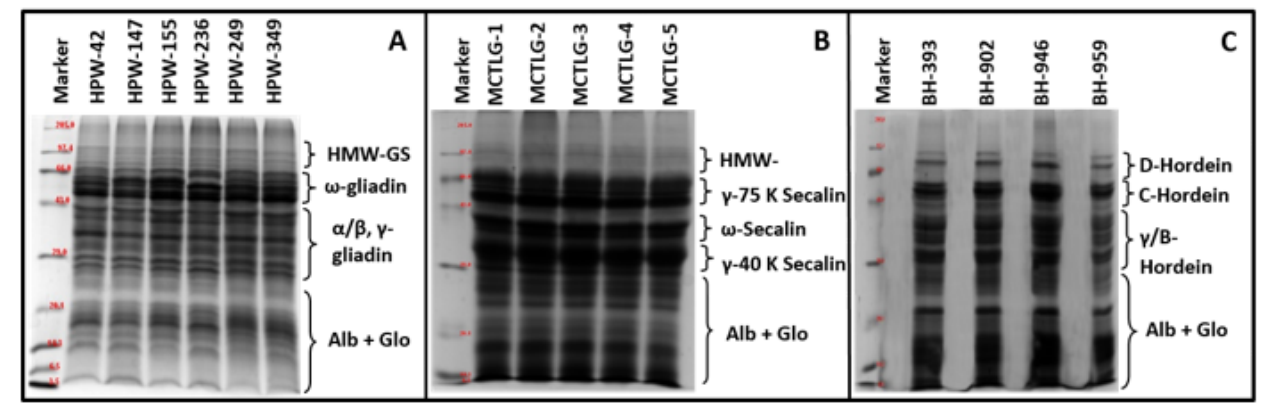

Figure 3 


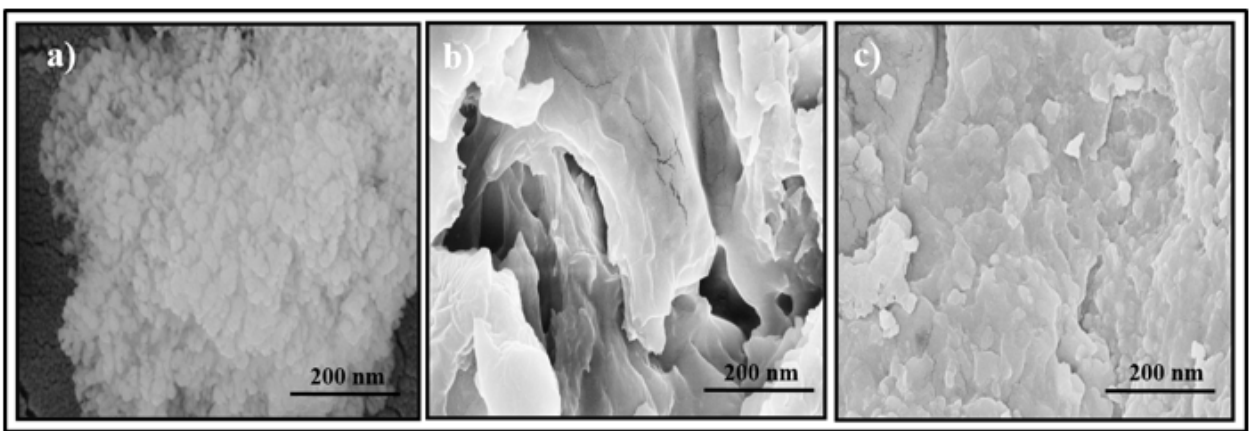

\section{Figure 4}

SEM micrograph of (a) Gliadin, (b) Secalin (c) Hordein.
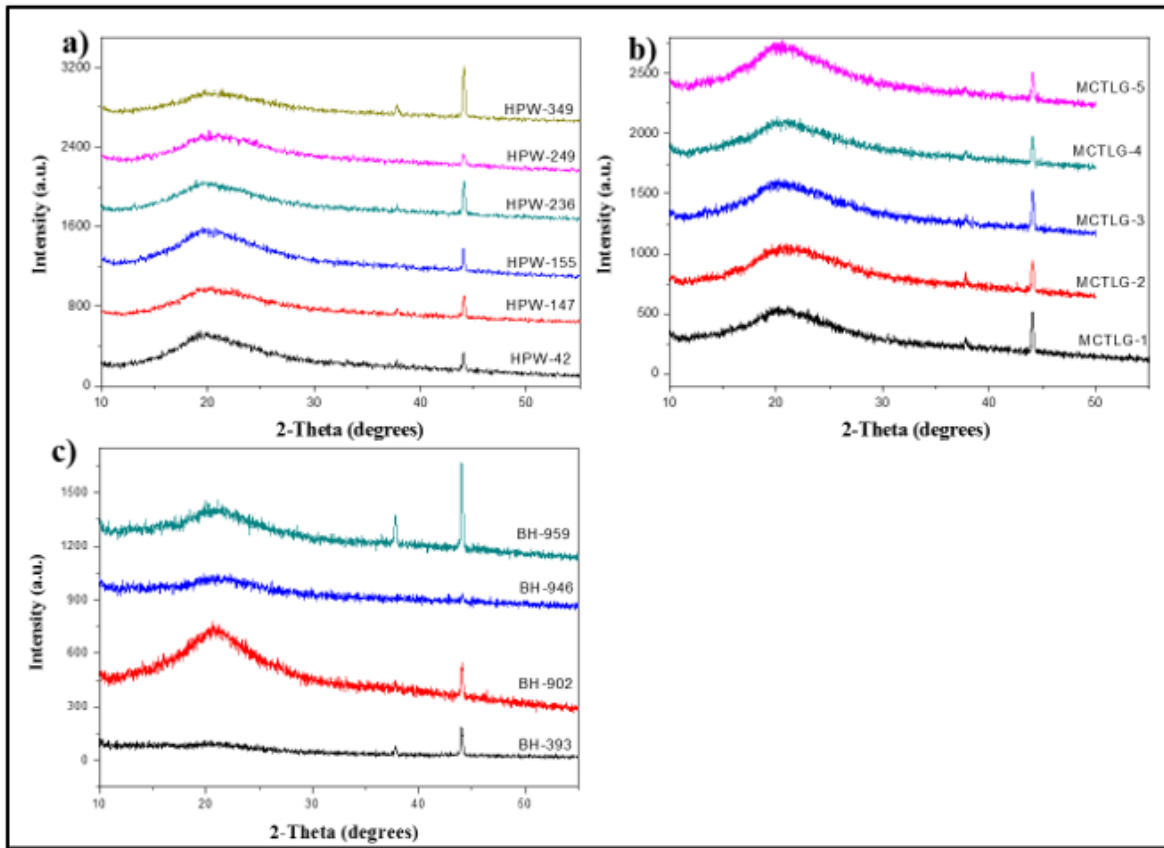

Figure 5

Original X-ray diffractograms of (a) Gliadin, (b) Secalin and (c) Hordein. 


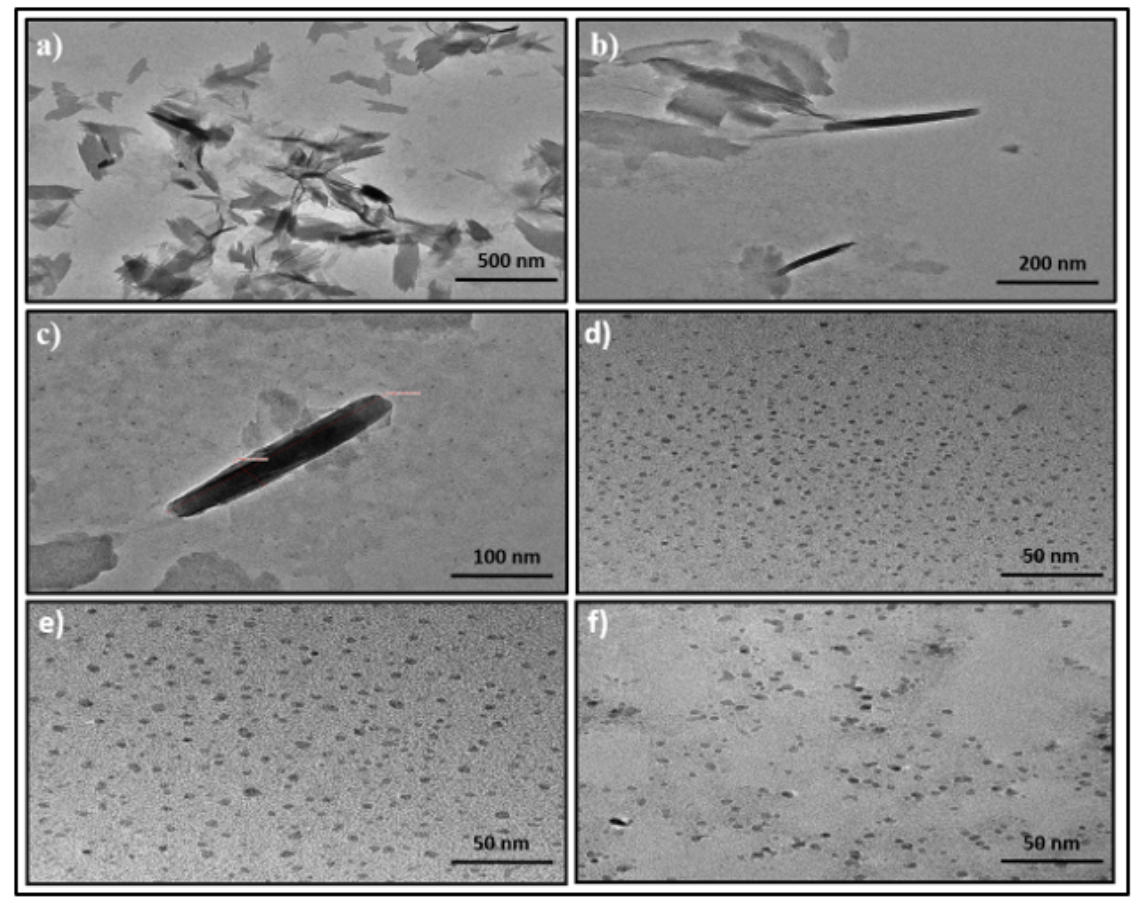

Figure 6

TEM micrograph of (a) rod shaped Gliadin at 500nm, (b) rod shaped Gliadin at 200nm(c) rod shaped Gliadin at 100nm, beneath globular shaped gliadin also seen (d) globular shaped Gliadin at 50nm (e) Secalin at 50nm and (f) Hordein at 50nm.

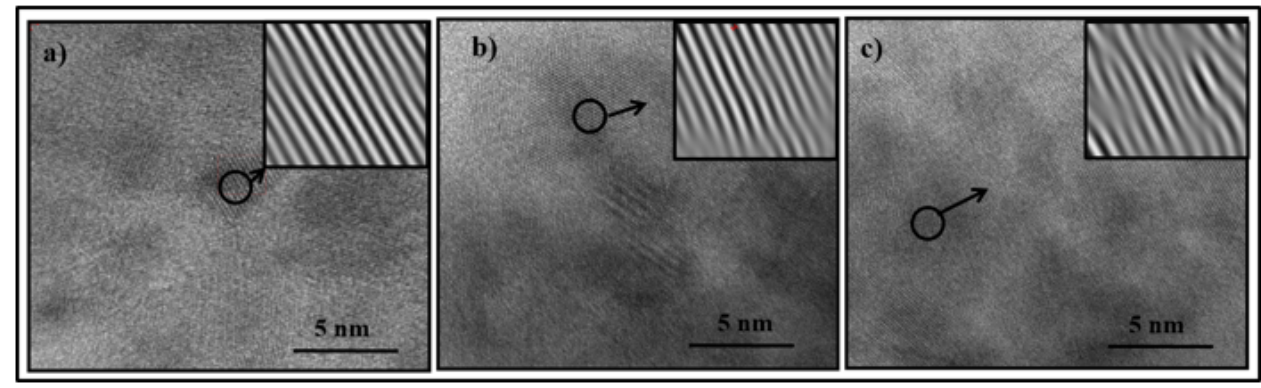

\section{Figure 7}

Interplanar spacing (d-spacing) from TEM-selected area electron diffraction (SAED) lattice pattern showing crystallinity in peptides of (a) Gliadin, (b) Secalin and (c) Hordein.

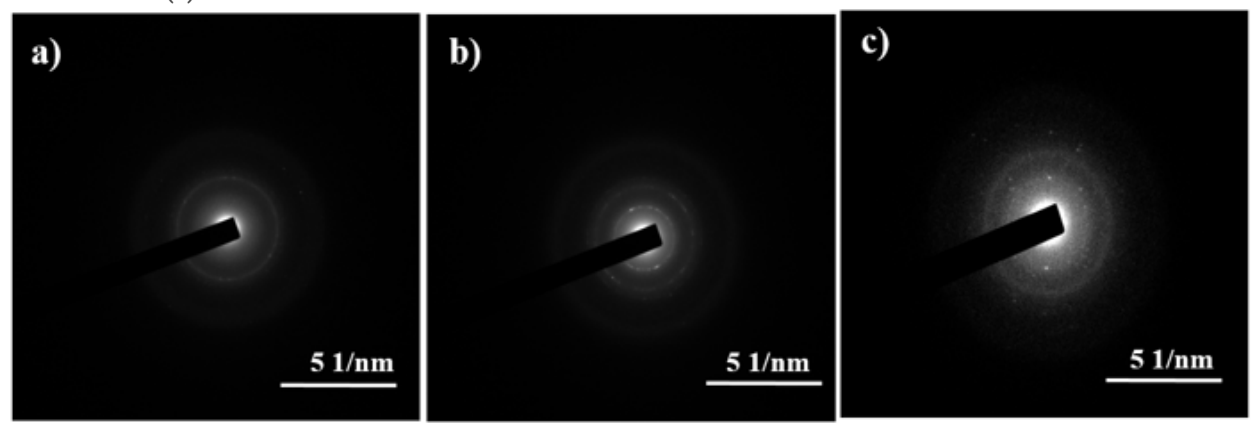

\section{Figure 8}

Micrograph of TEM-Selected area electron diffraction (SAED) ring pattern (a) Gliadin, (b) Secalin and (c) Hordein

\section{Supplementary Files}

This is a list of supplementary files associated with this preprint. Click to download.

- ProlaminSItablesfinal060321.docx 